\title{
Determination of Critical Criterion of Tensile-shear Failure in Brazilian Disc Based on Theoretical Analysis and Meso-macro Numerical Simulation
}

\section{Zenghui Zhao}

Shandong University of Science and Technology

\section{Peng Yang}

Shandong University of Science and Technology

Shaojie Chen ( $\nabla$ csjwyb@163.com )

Shandong University of Science and Technology

Dawei Yin

Shandong University of Science and Technology

Hao Liu

Shandong University of Science and Technology

\section{Bosen Chen}

Shandong University of Science and Technology

\section{Research}

Keywords: Brazilian disc, compression-tension ratio, critical criterion, meso-macro damage

Posted Date: November 5th, 2020

DOI: https://doi.org/10.21203/rs.3.rs-100955/v1

License: () (1) This work is licensed under a Creative Commons Attribution 4.0 International License.

Read Full License

Version of Record: A version of this preprint was published at Computers and Geotechnics on June 1st, 2021. See the published version at https://doi.org/10.1016/j.compgeo.2021.104096. 


\title{
Determination of Critical Criterion of Tensile-shear Failure in Brazilian Disc Based on Theoretical analysis and Meso-macro Numerical Simulation
}

\author{
Zenghui Zhao ${ }^{1,2}$, Peng Yang ${ }^{1}$, Shaojie Chen ${ }^{1,2, *}$, Dawei Yin ${ }^{1,2}$, Hao Liu ${ }^{1}$, Baosen Chen ${ }^{1}$ \\ 1 College of Energy and Mining Engineering, Shandong University of Science and Technology, Qingdao \\ 266590, China; \\ 2 State Key Laboratory of Mining Disaster Prevention and Control Co-founded by Shandong Province and \\ the Ministry of Science and Technology, Qingdao 266590, China;
}

* Correspondence:csjwyb@163.com

\begin{abstract}
To define the critical criterion between tensile failure and shear failure of Brazilian disc is crucial for determination of tensile strength under combination of tensile and compressive stresses. Although Griffith's tensile failure criterion is consistent with theoretical solution of radial splitting disc, there are still some shortcomings in which the compressiontension ratio is regarded as a constant and the critical criterion only depend on single parameter of tensile strength. Therefore a critical criterion for tensile-shear failure including tensile truncation was proposed firstly based on Mohr-Coulomb criterion. Then, a new calculation method of shear strength parameters was deduced based on the critical state stress circle. Finally, effective diameter and range of compression-tension ratio of Brazilian disc under tensile failure are proposed, and failure process of Brazilian disc from meso to macro is carried out based on numerical simulation. The results show that the modified Mohr-Coulomb criterion can be determined by two indexes of compressive strength and tensile strength. The deduced compression-tension ratio is in good agreement with experiment results. The accuracy of tensile strength test results is closely related to this ratio. When the ratio is greater than 6 , failure of rock can be regarded as ideal tensile failure. If the ratio is less than 6 , wedge-shape failure in loading area is the main failure type. On this condition, even if radial crack occurs, it is still not considered to be caused by pure tension.
\end{abstract}

Keywords: Brazilian disc, compression-tension ratio, critical criterion, meso-macro damage

\section{Introduction}

As quasi-brittle material, tensile strength of rock is far lower than compressive strength due to existence of micro cracks, pores and other defects. Although rock in underground often suffer complex combined stress states of tension, compression and shear, failure mechanism can only be divided into two types: tensile failure and shear failure. Therefore, tensile strength is an important mechanical property of rock, and also a control parameter of safety design and 
stability analysis of rock engineering. Accurate prediction of tensile strength of rock is very important for maintaining safety of underground space development and energy exploitation (Zhao et al. 2020).

As a general method to determine tensile strength of rock-like brittle material, Brazilian disc splitting test has been written into the relevant technical specifications of China, Japan, the United States, the United Kingdom and other countries(ISRM 1978; Yangtze River Scientific Research Institute 2001). Although this test method is mature and widely used, it is still a research hotspot which mainly focuses on the following aspects. The first is focusing on the applicability of Brazilian splitting test as a plane problem, i.e. the size effect problem (Aliha 2014; Serati et al. 2014; Wang et al. 2013; Yu 2005). Some results showed that Brazilian splitting test was fundamentally a three-dimensional elastic problem, and factors influencing stress distribution were not only external force, but also ratio of height to diameter and Poisson's ratio of material. In addition to the stress concentration area, the maximum tensile stress appeared in the center of two end faces, which lead to large experimental errors. Secondly, the improvement of disc's force conditions was focused, i.e. the loading modes. In order to reduce the local stress concentration in loading area, researchers proposed arc loading mode, platform loading mode, ring loading mode, semicircle disk loading mode, etc.(Ayatollahi et al.2016; Kourkoulis et al. 2013; Lin et al. 2015; Wu et al. 2015; Yu et al. 2018; Yuan and Shen 2017). A lot of experiments and theoretical studies had been carried out to solve these problems, such as theoretical solutions to load modes, mechanical behavior of loading interface, optimal loading angle, micro and macro failure characteristics, etc., which improve experimental accuracy of Brazilian disc splitting test. Thirdly, the splitting characteristics of rock fabric (including defects, joints, bedding, etc.) and unconventional state (considering water, high temperature, dynamic loading) were studied, such as influence of different loading rates, bedding direction, rock interface effecting on tensile strength and failure characteristics (Claesson and Bohloli.2002; Markides et al. 2016; Tavallali and Vervoort 2010), deformation and strength characteristics of rock under transient dynamic load and fatigue load(Li et al. 2005;Zhu et al. 2005), splitting failure modes of rock under dry and different water content, etc. ( Wang et al. 2017; You et al. 2011) The relevant acoustic emission (AE) and energy evolution analysis also provide a lot of data for understanding the splitting failure mechanism.

The Brazilian splitting test method is simple and easy to operate, not requiring special equipment. An ordinary press machine can be used for testing. However, many test results show that the tensile strength obtained by the Brazilian disc splitting test is significantly different from that obtained by the direct tensile method. For this reason, some scholars have questioned 
applicability of the Brazilian disc splitting test. For example, influence of stress space, threedimensional solution and plane solution can cause errors of up to 10\% (Chau and Wei 2001), And this error is not considered in the calculation formulas, which causes problems in applicability of tensile failure criterion of rock. The maximum tensile stress criterion, MohrCoulomb (M-C) strength criterion, and Griffith strength criterion are often used for tensile failure of rock material. However, the tensile strength of rock obtained by these criterions is significantly different from tensile strength obtained by direct tensile tests. This has been verified by a large number of experiments (Han et al. 2016; Lyu et al. 2019; Perras and Diederichs 2014; Zhang and Liu 2016). In addition, different loading methods will cause local damage to loading area, resulting in a large difference between strength of Brazilian disc and actual value.

For these reasons, some scholars consider that Brazilian disc splitting test cannot be used to measure tensile strength of rock material. From these results, it is not that the Brazilian disc splitting test is not suitable for measurement in nature, but that the criterion for rock tensile failure is not accurate. Rock discs undergo complex tension and compression combined stress states during the splitting process. The apparent failure mode of the rock is splitting, but it may not be entirely caused by tensile cracking, and may also include shear failure. Whether the disc manifests as tensile failure or shear failure, or whether there are other intermediate states between the two failure types, and where the critical point between two failure types are all not clear. To this end, in this paper, a critical criterion for tensile or shear failure is proposed for the radial splitting of the disc. Through numerical simulation, the whole process of damage from micro damage to macro failure of the disc is also analyzed and the quantitative index of Brazilian splitting tension shear conversion is put forward.

\section{Critical criterion of tensile-shear failure in Brazilian disc under radial loading}

2.1 Critical stress state under combined action of tension-compression stresses

From perspective of fracture mechanics, Griffith proposed following strength criterion based on the stress analytical solution of elliptical hole (Yu 2004),

$$
\begin{aligned}
& \sigma_{1}+3 \sigma_{3}>0, \quad \frac{\left(\sigma_{1}-\sigma_{3}\right)^{2}}{\sigma_{1}+\sigma_{3}}=8 \sigma_{\mathrm{t}} \\
& \sigma_{1}+3 \sigma_{3}<0, \quad \sigma_{3}=-\sigma_{\mathrm{t}}
\end{aligned}
$$

The function of Griffith's criterion theory is a piecewise function. The schematic diagram of the strength theory in the $\sigma_{1} \sim \sigma_{3}$ coordinate system is shown in Fig. 1. When the stress satisfies $\sigma_{1}+3 \sigma_{3}<0$, regardless the value of $\sigma_{1}$, cracks in rock begin to spread as long as 
$\sigma_{3}=-\sigma_{\mathrm{t}}$ is satisfied. Second, when stress satisfies $\sigma_{1}+3 \sigma_{3}>0$, the failure criterion is a quadratic curve, which is connected to above criteria at $\left(3 \sigma_{t},-\sigma_{t}\right)$.

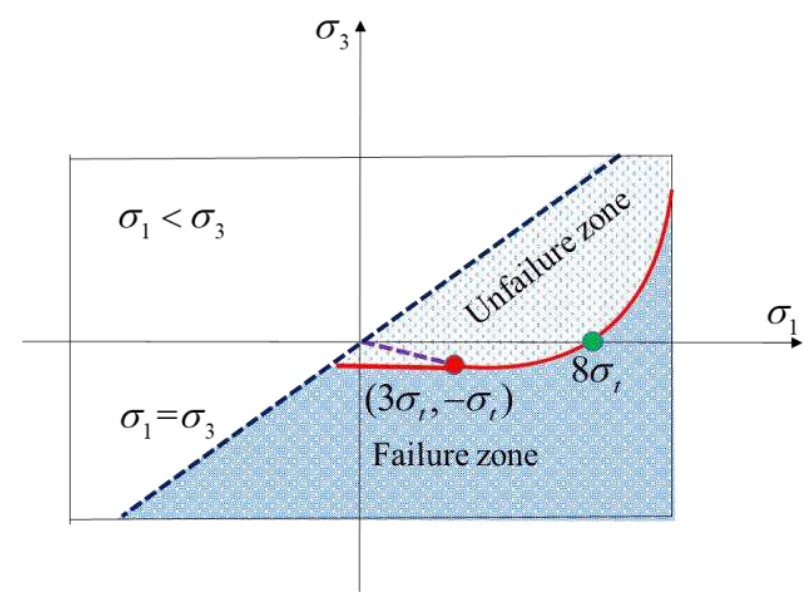

Fig. 1 Griffith strength criterion

Because compressive stress at center point of disc is exactly three times of tensile stress, which is consistent with the Griffith tensile strength criterion. Therefore, many scholars have taken this as failure reason of disc splitting. However, several problems are worthy of further discussion as follows:

(1) The intersection of quadratic curve segment and $\sigma_{1}$ is $8 \sigma_{t}$, that is, according to the theory, no matter what type of rock, the uniaxial compressive strength is 8 times uniaxial tensile strength, which is not consistent with many experimental results. The compression-tension ratios of different types of rock material are quite different.

(2) The critical point of the strength criterion for rock to undergo tensile or shear failure is $\left(\sigma_{3}, \sigma_{1}\right)=\left(-\sigma_{\mathrm{t}}, 3 \sigma_{\mathrm{t}}\right)$. This state can be regarded as a critical stress state, The critical point is completely determined by single index $\sigma_{t}$, which cannot reflect impact of compressive strength of rock.

The M-C criterion has been widely used in the field of geotechnical engineering in past hundred years due to consideration of rock tensile and compressive shear stress states. For biaxial compression, normal and shear stresses on failure surface satisfy

$$
\tau=C+\sigma \tan \varphi
$$

where $C$ is the cohesion of rock, $\varphi$ is the friction angle. Assuming that the apparent uniaxial tensile strength and uniaxial compressive strength of rock are $\sigma_{\mathrm{t}}$ and $\sigma_{\mathrm{c}}$, respectively, then

$$
C=\frac{\sqrt{2}}{4} \sigma_{\mathrm{c}} \tan \left(45^{\circ}-\varphi / 2\right), \quad \sigma_{\mathrm{t}}=\sigma_{\mathrm{c}} \tan ^{2}\left(45^{\circ}-\varphi / 2\right)
$$

In terms of principal stress, the M-C criterion can be expressed as 


$$
\sigma_{1}=\sigma_{3} \tan ^{2}\left(45^{\circ}+\frac{\varphi}{2}\right)+\sigma_{\mathrm{c}}
$$

If the criterion is to be applied, normal stress on the failure surface should satisfy

$$
\sigma=\frac{\sigma_{1}+\sigma_{3}}{2}+\frac{\sigma_{1}-\sigma_{3}}{2} \cos 2 \alpha \geq 0
$$

Since azimuth of failure surface is satisfied $\cos 2 \alpha=-\sin \varphi$, the following is obtained by substituting Eq. (4) into Eq. (5)

$$
\sigma_{1} \geq \frac{\sigma_{\mathrm{c}}}{2}
$$

That is, the M-C criterion is valid only when maximum principal stress is greater than half of uniaxial compressive strength. At this time, rock shows shear failure, otherwise it is determined by tensile strength. Thus, the $\mathrm{M}-\mathrm{C}$ criterion with tensile truncation is presented in Fig. 2 and the expression is

$$
\begin{aligned}
& \sigma_{1} \geq \frac{1}{2} \sigma_{\mathrm{c}}, \quad \sigma_{1}=\sigma_{3} \tan ^{2}\left(45^{\circ}+\frac{\varphi}{2}\right)+\sigma_{\mathrm{c}} \\
& \sigma_{1} \leq \frac{1}{2} \sigma_{\mathrm{c}}, \quad \sigma_{3}=-\sigma_{\mathrm{t}}
\end{aligned}
$$

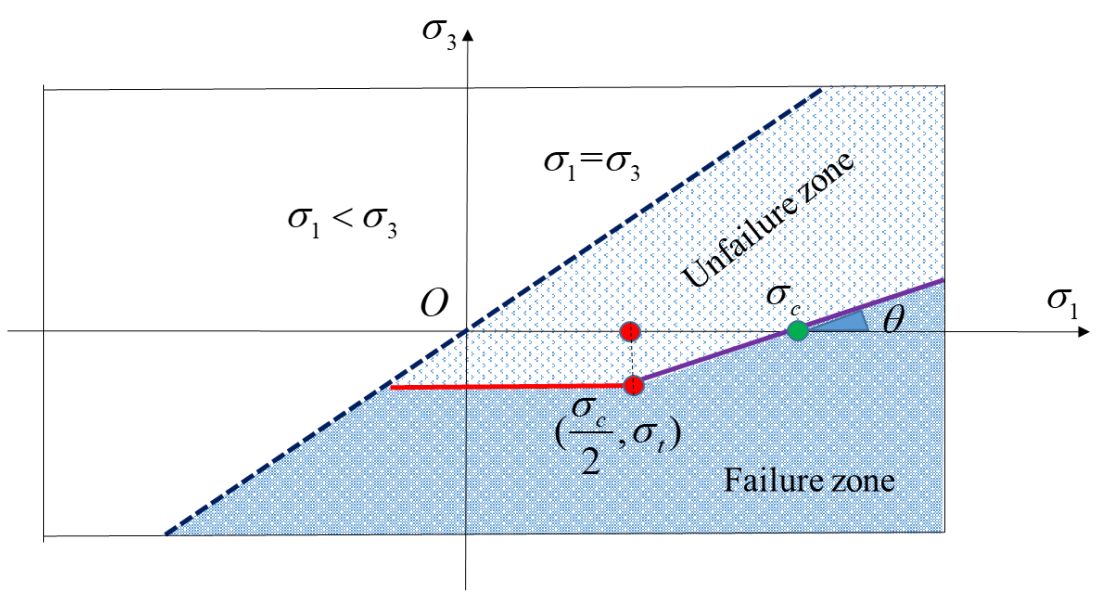

Fig. 2 Modified Mohr-coulomb criterion

According to above analysis, the critical stress state of the $\mathrm{M}-\mathrm{C}$ criterion for tensile or shear failure should be $\left(\sigma_{3}, \sigma_{1}\right)=\left(-\sigma_{\mathrm{t}}, 0.5 \sigma_{\mathrm{c}}\right)$. The stress circle drawn by the critical stress state can be used as critical circle for tensile or shear failure of rock under combined tensile and compression stress. (Tao 1990). Bounded by this state, the ultimate stress circle on the right is shear failure, and one on left is tensile failure. In this way, critical states of tensile or shear failure of traditional M-C criterion, modified M-C criterion, and Griffith criterion under combined tensile and compression stresses can be respectively summarized as follows:

(1) Traditional M-C criterion, $\left(\sigma_{3}, \sigma_{1}\right)=\left(-\sigma_{\mathrm{t}}, 0\right)$ 
(2) Modified M-C criterion, $\left(\sigma_{3}, \sigma_{1}\right)=\left(-\sigma_{\mathrm{t}}, 0.5 \sigma_{\mathrm{c}}\right)$

(3) Griffith criterion, $\left(\sigma_{3}, \sigma_{1}\right)=\left(-\sigma_{\mathrm{t}}, 3 \sigma_{\mathrm{t}}\right)$

For quantitative analysis, Fig 3 presented the strength straight line envelopes determined by the ultimate stress circle based on the three methods. The traditional M-C criterion strength parameters determined by uniaxial tension and uniaxial compression (indicated by the dashed lines in Fig. 3) have been introduced in many studies. Here we just analyze the others. The parameters determined by the critical stress state stress circle and uniaxial compressive stress circle tangent are marked by $\mathrm{M}$ and $\mathrm{G}$, which obtained using the $\mathrm{M}-\mathrm{C}$ criterion and the Griffith criterion, respectively.

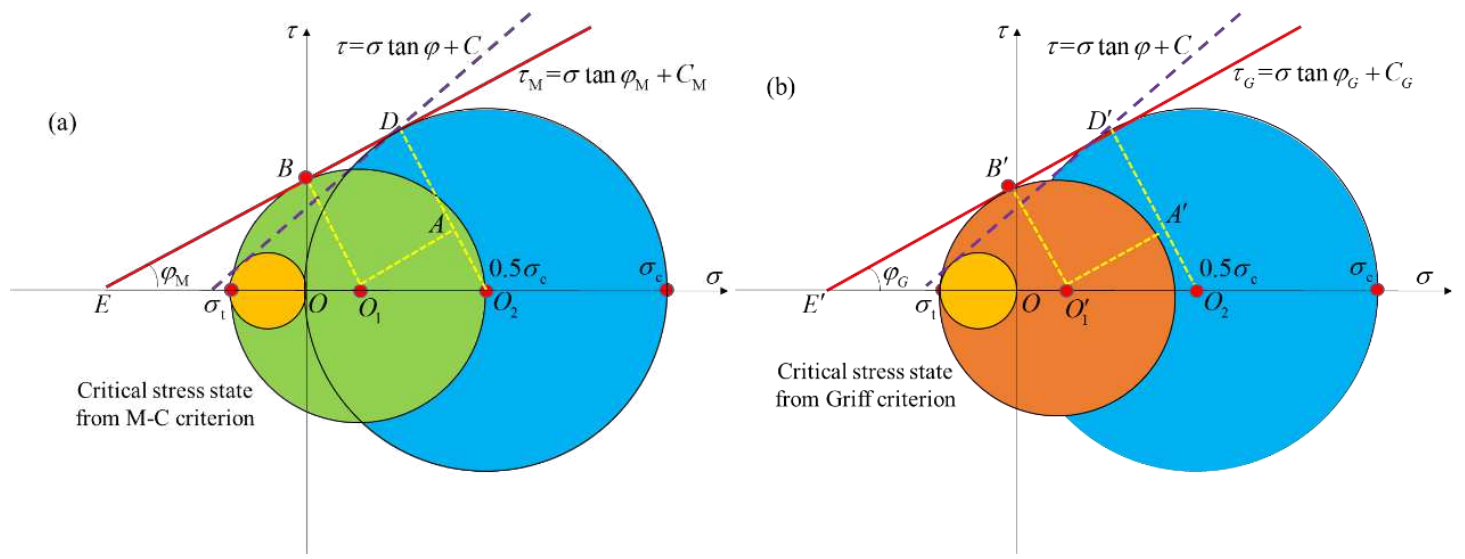

(a) The critical stress state with $\left(\sigma_{3}, \sigma_{1}\right)=\left(-\sigma_{t}, 0.5 \sigma_{\mathrm{c}}\right)$;(b)The critical stress state with $\left(\sigma_{3}, \sigma_{1}\right)=\left(-\sigma_{t}, 3 \sigma_{t}\right)$

Fig. 3 Determination of strength parameters using stress circles of critical stress state

According to $\triangle O_{2} D E, \triangle O_{1} O_{2} A$ and $\triangle O O_{1} B$ in Fig. 3 (a), it is easy to get

$$
\sigma_{\mathrm{c}}=\frac{2 C_{\mathrm{M}} \cos \varphi_{\mathrm{M}}}{1-\sin \varphi_{\mathrm{M}}}, \sigma_{\mathrm{t}}=\frac{\sigma_{\mathrm{c}}}{2} \tan ^{2}\left(45^{\circ}-\varphi_{\mathrm{M}} / 2\right), C_{\mathrm{M}}=\frac{\sigma_{\mathrm{c}}}{2} \tan \left(45^{\circ}-\varphi_{\mathrm{M}} / 2\right)
$$

Where $C_{\mathrm{M}}$ and $\varphi_{\mathrm{M}}$ are the modified cohesion and internal friction angle, respectively. It is worth noting that $\sigma_{\mathrm{t}}$ is not actual measured uniaxial tensile strength, because this value is calculated using strength curve. In negative semi-axis, M-C strength curve should be truncated. Compared with Eq. (3), it is easy to know that uniaxial compressive strength has no change in form, but relationship between apparent tensile strength and cohesive force and compressive strength changes. According to $\Delta O_{2} D^{\prime} E^{\prime}, \Delta O_{1}^{\prime} O_{2}^{\prime} A^{\prime}$ and $\triangle O O_{1}^{\prime} B^{\prime}$ in Fig. 3 (b), 


$$
\sigma_{\mathrm{t}}=\frac{\sigma_{\mathrm{c}}}{2}\left(\frac{1-\sin \varphi_{G}}{2-\sin \varphi_{G}}\right), \quad C_{\mathrm{G}}=\sqrt{3} \sigma_{\mathrm{t}}
$$

In addition, following relations can be obtained

$$
\sin \varphi=\frac{\sigma_{c}-\sigma_{t}}{\sigma_{c}+\sigma_{t}}, \quad \sin \varphi_{\mathrm{M}}=\frac{\sigma_{c}-2 \sigma_{t}}{\sigma_{c}+2 \sigma_{t}}, \sin \varphi_{\mathrm{G}}=\frac{\sigma_{c}-4 \sigma_{t}}{\sigma_{c}-2 \sigma_{t}}
$$

Thus, ratio of uniaxial compressive strength to tensile strength (compression-tension ratio) before and after modification can be calculated as

$$
\begin{aligned}
& \kappa=\tan ^{2}\left(45^{\circ}+\varphi / 2\right) \\
& \kappa_{\mathrm{M}}=2 \tan ^{2}\left(45^{\circ}+\varphi_{\mathrm{M}} / 2\right) \\
& \kappa_{G}=2+\frac{2}{1-\sin \varphi_{\mathrm{G}}}
\end{aligned}
$$

$\mathrm{Li}$ (Li 1983) listed test results of friction angle and compression-tension ratio of shale, sandstone, marble, granite, etc. The comparison between calculation results of Eq. (10) and test results are illustrated in Fig. 4. By comparison, the modified $\mathrm{M}-\mathrm{C}$ criterion based on critical stress state and uniaxial compressive stress circle agrees best.

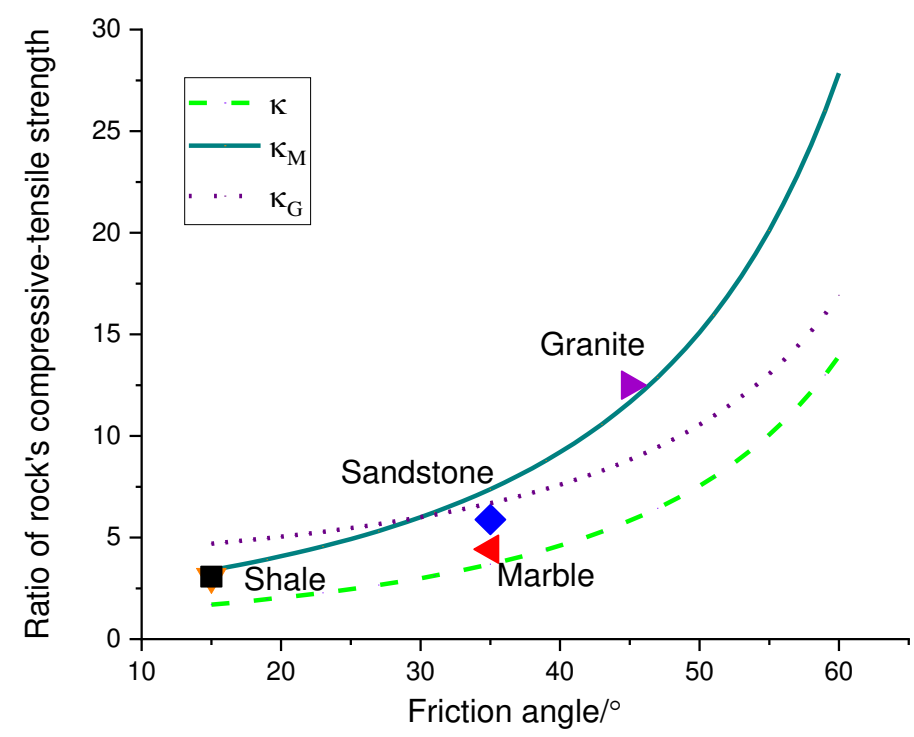

Fig. 4 Comparison between theoretical and experimental results

Slope of shear strength curve in Fig. 3 (a) is determined by $\tan \theta=2 \sigma_{t} / \sigma_{c}=2 / \kappa_{\mathrm{M}}$. In other words, the modified M-C strength under complex stress conditions can be completely determined by $\sigma_{\mathrm{t}}$ and $\sigma_{\mathrm{c}}$. The critical stress state determined by $\left(\sigma_{3}, \sigma_{1}\right)=\left(-\sigma_{\mathrm{t}}, 0.5 \sigma_{\mathrm{c}}\right)$ can be used as a threshold to distinguish tensile failure and shear failure of Brazilian disc. Based on this state, limit stress state on the right will undergo shear failure. The left limit states are all 
tensile failures, and a series of intermediate states between single tensile failure and critical states are all controlled by tensile strength.

\subsection{Analytical solution of effective tensile failure zone in Brazilian disc}

According to the analytical solution of plane stress problem in elastic mechanics, stress at any point $M(x, y)$ in disc is
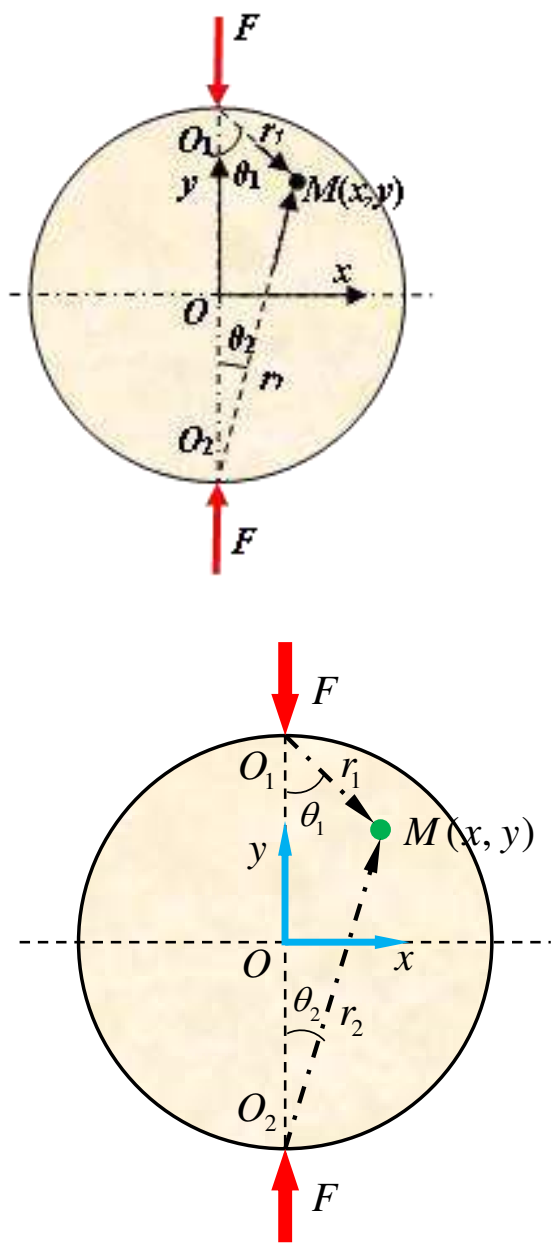

Fig.5 Brazilian disc under radial splitting

$$
\begin{aligned}
& \sigma_{x}=-\frac{2 F}{\pi}\left[\frac{(a-y) x^{2}}{r_{1}^{4}}+\frac{(a+y) x^{2}}{r_{2}^{4}}-\frac{1}{d}\right] \\
& \sigma_{y}=\frac{2 F}{\pi}\left[\frac{(a-y)^{3}}{r_{1}^{4}}+\frac{(a+y)^{3}}{r_{2}^{4}}-\frac{1}{d}\right] \\
& \tau_{x y}=\frac{2 F}{\pi}\left[\frac{(a-y)^{2} x}{r_{1}^{4}}-\frac{(a+y)^{2} x}{r_{2}^{4}}\right]
\end{aligned}
$$

On loading line, there is $x=0, r_{1}=a-y, r_{2}=a+y$, so the stress can be rewritten as 


$$
\begin{aligned}
& s_{x}=-\frac{2 F}{\pi d}
\end{aligned}
$$

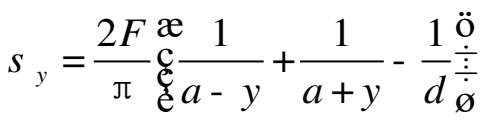

$$
\begin{aligned}
& t_{x y}=0
\end{aligned}
$$

That is, on the loading line, $\sigma_{3}=\sigma_{x}, \sigma_{1}=\sigma_{y}$. the failure of the disc is completely controlled by the tensile strength when compressive stress on failure surface is less than $50 \%$ of compressive strength according to the modified M-C strength criterion in Section 2.1. Defining the effective compression-tension ratio for tensile failure as

$$
k_{\mathrm{e}}=\frac{s_{y}}{s_{x}}=\frac{\frac{1}{2} s_{\mathrm{c}}}{s_{\mathrm{t}}}=\frac{1}{2} k_{\mathrm{M}}
$$

Substituting Eq. (12) into Eq. (13), effective tensile fracture diameter is determined as

$$
D_{e}=d \sqrt{\frac{k_{\mathrm{M}}-6}{k_{\mathrm{M}}+2}}
$$

Thus, if the disc has an effective tensile diameter, the compression-tension ratio should be satisfied $\kappa_{\mathrm{M}}>6$. Within this range, if disc cracks within effective diameter (not necessarily at the center of the circle), it can be regarded as an ideal tensile fracture. However, if $\kappa_{\mathrm{M}}<6$, even if the disk cracks from the center, it cannot be considered as an ideal tensile fracture, which may include shear failure.This may cause large deviation between the experimental result and the true value.

\section{Splitting failure analysis of rock discs under different compression- tension ratios}

\subsection{Calculation model}

In numerical simulation software of RFPA (Realistic Failure Process Analysis), calculation model is made up of some basic elements with different properties (such as elastic modulus, strength, Poisson's ratio, etc.) which obey some statistical natures such as the Weibull distribution. It can realize the complex failure process of materials at macro level from micro scope by using elastic damage constitutive model. In this way, it is convenient to discuss the influence of micro material parameters of basic element on macro mechanical behavior, including ratio of compressive strength to tensile strength. Considering ratio of compressivetensile strength proposed in section 2, the following modified M-C criterion with tensile 
truncation is adopted,

$$
\begin{cases}\sigma_{1}-\sigma_{3} \tan ^{2}\left(45^{\circ}+\frac{\varphi}{2}\right)-\sigma_{c} \geq 0 & \sigma_{1} \geq\left(1-\frac{\tan ^{2}\left(45^{\circ}+\frac{\varphi}{2}\right)}{\kappa_{\mathrm{M}}}\right) \sigma_{\mathrm{c}} \\ \sigma_{3}+\sigma_{\mathrm{t}} \leq 0 & \sigma_{1} \leq\left(1-\frac{\tan ^{2}\left(45^{\circ}+\frac{\varphi}{2}\right)}{\kappa_{\mathrm{M}}}\right) \sigma_{\mathrm{c}}\end{cases}
$$

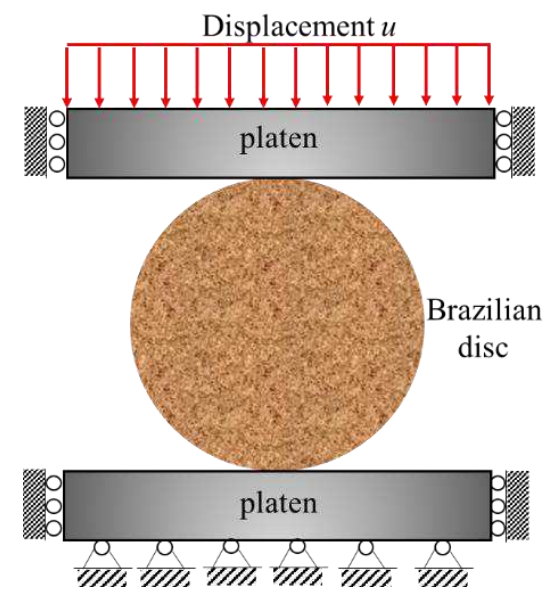

Fig. 6 Model of Brazilian disc under radial splitting

The calculation model of Brazilian disc is shown in Fig. 6. The size of entire model is $100 \mathrm{~mm} \times 100 \mathrm{~mm}$, the diameter of disc is $80 \mathrm{~mm}$, and thickness of pressure plate is $10 \mathrm{~mm}$. The whole model was divided into 90,000 elements. The horizontal and vertical displacements at the bottom were both fixed. For the loading platen, only displacement in loading direction is allowed. Considering the cushion effect between loading platen and disc during actual loading, the loading platen is set to be a uniform linear elastic body and material is the same as cushion with an elastic modulus of $10 \mathrm{Gpa}$ and a Poisson ratio of 0.25 . The average elastic modulus, Poisson's ratio, and uniaxial compressive strength of the model are set as $5 \mathrm{GPa}, 0.3$, and $50 \mathrm{Mpa}$ respectively according to the experimental results. The heterogeneity coefficient of disc is set as 8 . Loading mode is adopted displacement style with a speed of $0.004 \mathrm{~mm} / \mathrm{step}$.

\subsection{Results and discussion}

\subsubsection{Differences of stress-strain relations under various $\kappa_{\mathrm{M}}$}

Fig. 7 shows the full stress-strain curves of the discs with different $\kappa_{\mathrm{M}}$. The model with different compressive-tensile behaviors all undergone three stages, that is pre-peak elasticity, post-peak stress drops and residual deformation. During the pre-peak elastic stage, micro 
element does not break or only show sporadic failure, no cracks is formed, so pre-peak stage under different $\kappa_{\mathrm{M}}$ exhibit the same behavior with setting of same elastic modulus, this means tensile-compressive ratio had no effect on elastic deformation. In the peak area, number of sporadic damage elements in local area increases and cracks are produced through them, which could be regarded as initial stage of failure. On the whole, peak strength and residual strength of the model gradually decrease with increasing of $\kappa_{\mathrm{M}}$. Peak strengths are very close when $\kappa_{\mathrm{M}}=5,6,8$ while residual strengths are quite different. After the region is locally enlarged, it is found that strength drop rate after peak accelerates with increasing of $\kappa_{\mathrm{M}}$. But it had no large difference. This shows that macro strength is not significant changed when the compressiontension ratio is relatively small .Failureis not dominated by tensile strength. This is consistent with analysis conclusion of Section 2.

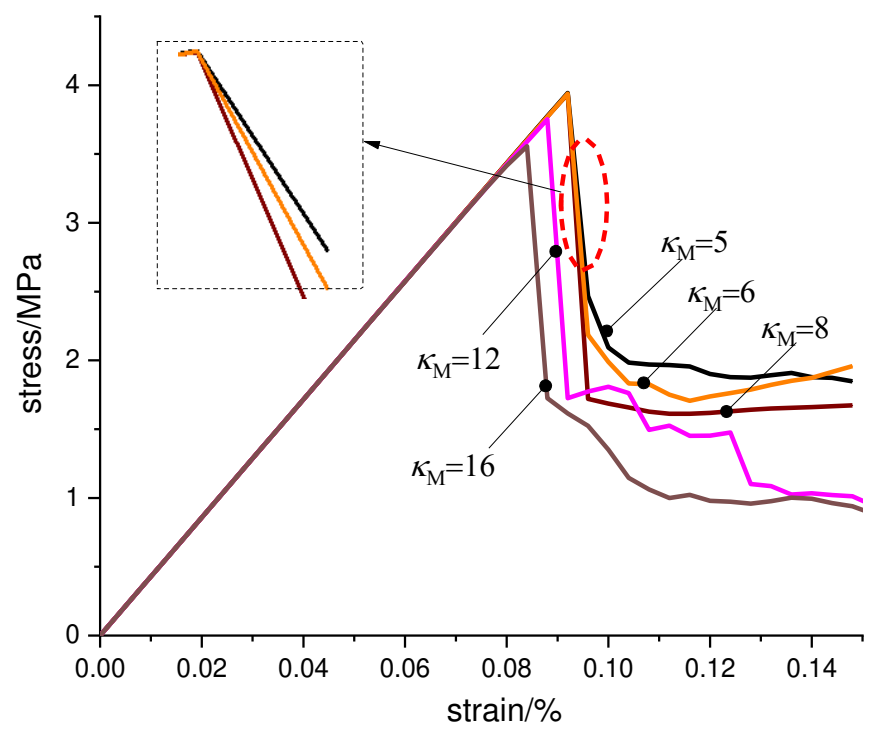

Fig.7 Stress-strain curves of Brazilian discs with different compression-tension ratios

\subsubsection{Failure characteristics of Brazilian disc with different $\kappa_{\mathrm{M}}$}

From Eq. (14), when $\kappa_{\mathrm{M}}$ is less than 6, failure of disc is controlled by shear strength, otherwise, it is determined by tensile strength. In order to further verify this conclusion. Fig. 8 presents failure process and $\mathrm{AE}$ characteristics of discs under different $\kappa_{\mathrm{M}}$. In AE diagram, the white circles represent shear failure and red represents tensile failure. When $\kappa_{\mathrm{M}}=5,6$, damage elements are concentrated near contact area between loading plate and disc, and a wedge-shaped failure pattern is formed with a short crack along the radial direction. From corresponding AE diagram, damage zones mainly exhibit shear failure near loading area which produces large compressive stresses both in horizontal and vertical direction, as well as shear stresses. When $\kappa_{\mathrm{M}}=8,10$ disc showed obvious cleavage failure, and failure elements produce a through crack along radial direction. From AE diagram, disc's failure appeared as tensile crack. 
Of course, the loading zone is also accompanied by shear failure due to contact extrusion.

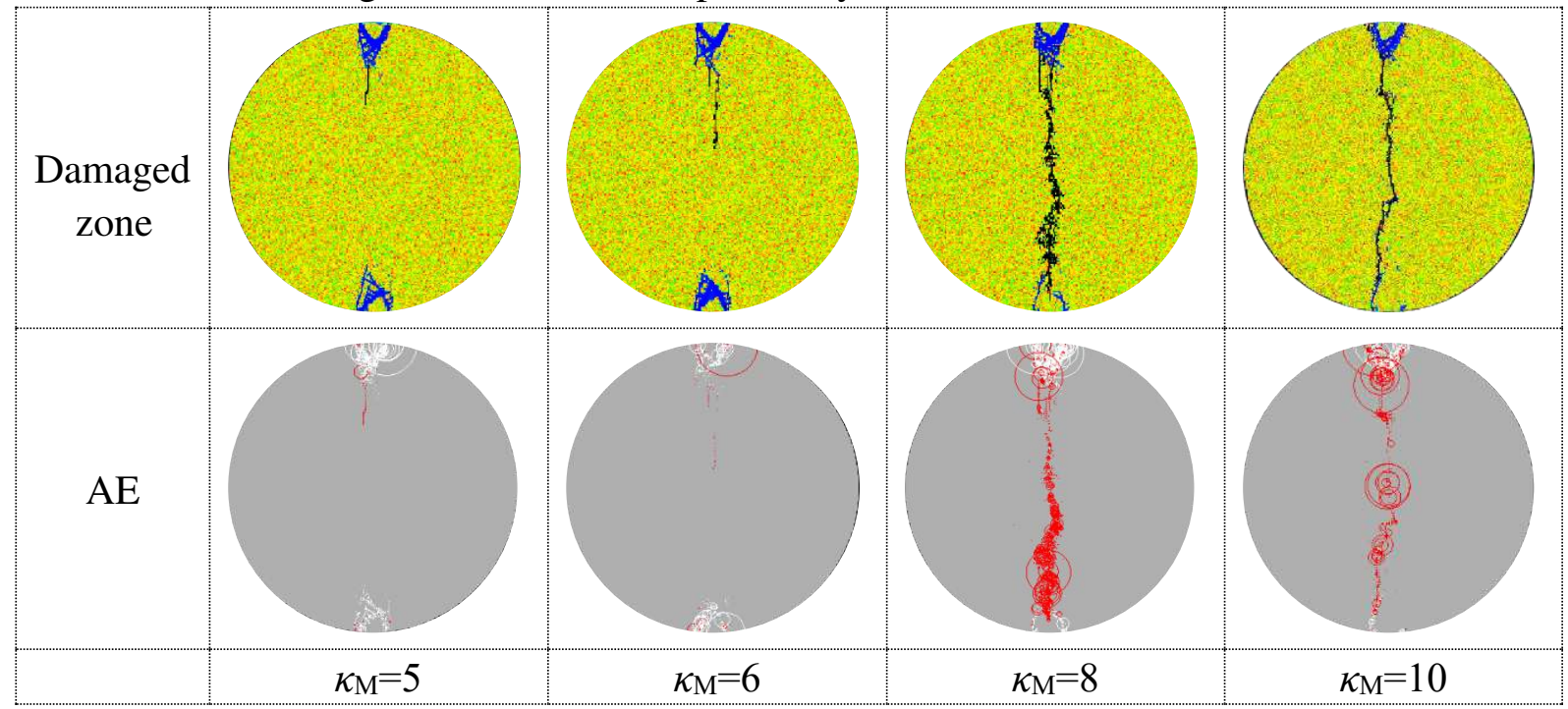

Fig. 8 Failure characteristics and AE of Brazilian discs with different $\kappa_{\mathrm{M}}$

In order to further illustrate the effect of ratio $\kappa_{\mathrm{M}}$ on failure morphology, Fig. 9 shows the corresponding relationship between failure process of micro element and stress loading curve when $\kappa_{\mathrm{M}}=6,10$. When $\kappa_{\mathrm{M}}=6$, sporadic damages first appear at loading contact zone before peak point. Because energy released by damage of these elements is less and no largescale crack is formed, stress curve of the whole specimen remains basically linear. With increase of loading, these damaged elements develop into through micro cracks (step 23), then wedge-shaped failure occurs at the contact position between disc and loading platen (step 24 and step 25). Subsequently, wedge-shaped body gradually expands along radial direction (step 40, step 55, and step 70), but extension depth is limited. For this ratio, failure of disc is concentrated in the wedge-shaped body which appeared as compression shear failure. When $\kappa_{\mathrm{M}}=10$, some tensile damage elements first appear in middle of sample before peak point (step 20). Due to the inhomogeneity of material, these elements are distributed in a certain width of area. When loading to peak point (step 24), the destruction elements start to gradually expand in radial direction. Due to sporadic distribution of element damage before peak, stress curve of entire sample still basically maintained a linear relationship. With the increase of external load, these damaged elements develop into tensile cracks and penetrate each other (step 25 , step 35, and step 40), resulting in cleavage failure in entire disc. At the same time, compression and shear damage occurs near the loading contact area, resulting in occurrence of secondary cracks. Such damage is ubiquitous in indoor experiments (Fig.10). 

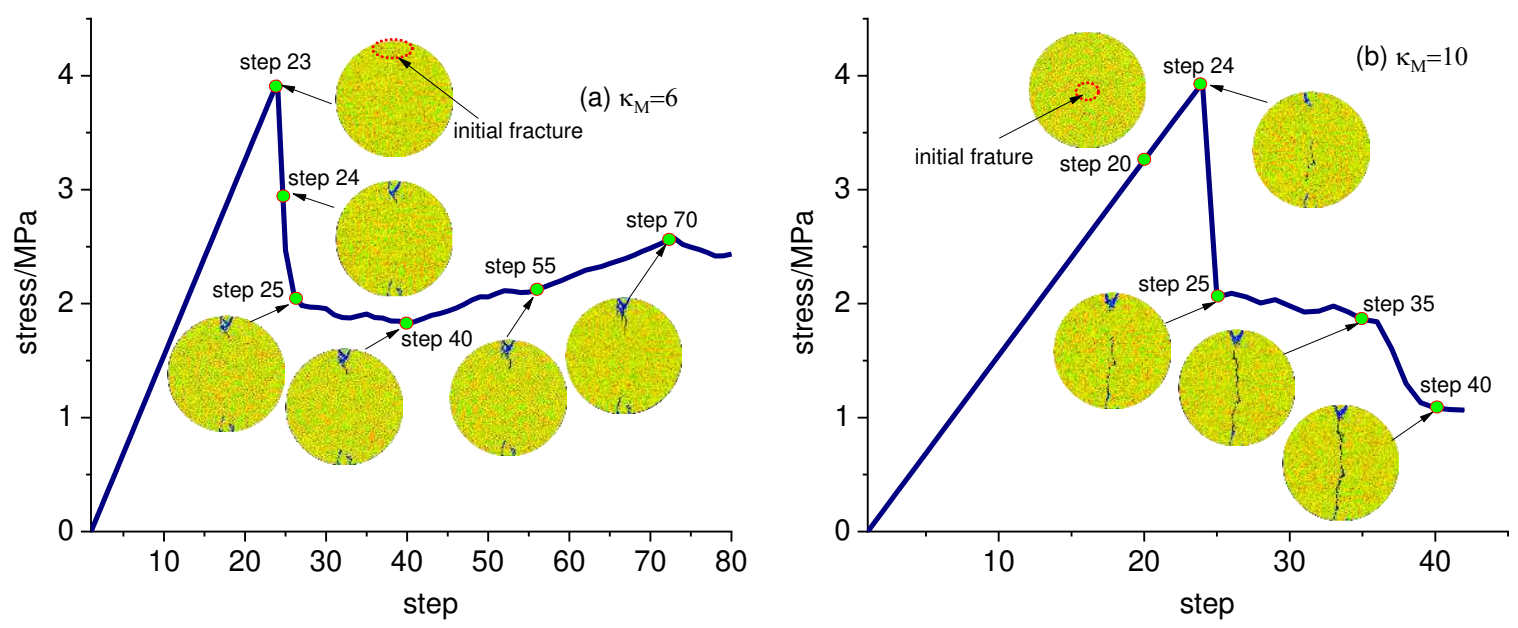

Fig. 9 Effect of compression-tension ratios on the failure evolution process of Brazilian discs

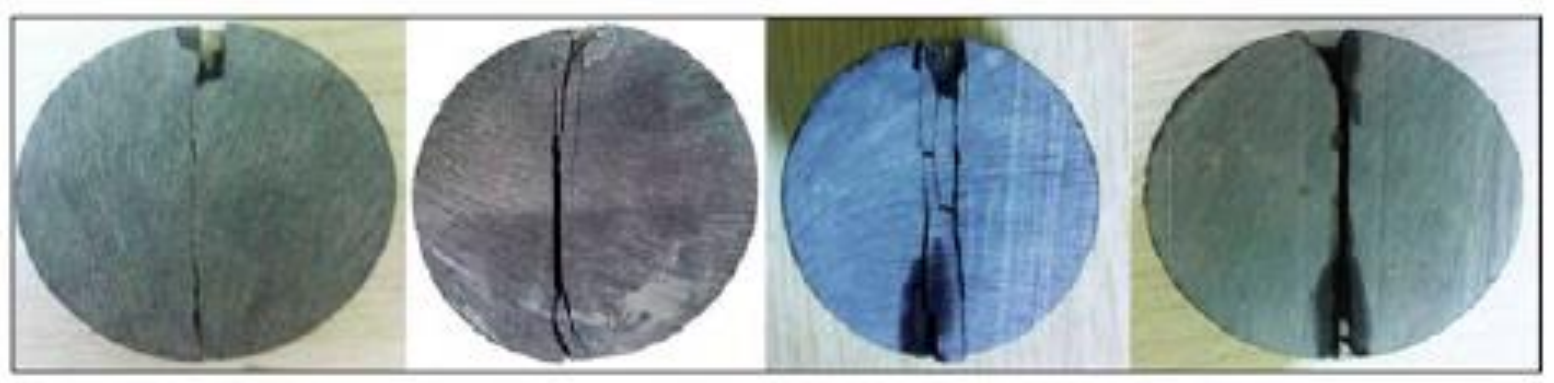

Fig.10 Split failure modes of Brazilian discs (Wang et al. 2017)

Fig. 11 shows the comparison of stress distribution at peak point along the loading diameter when $\kappa_{\mathrm{M}}$ is set as 6 and 10. Since the model is divided into 90,000 elements as a whole, several elements may be extracted at same location, so the stress distribution shows fluctuations. In fact, such fluctuations represent stress of different elements. Near loading platen, minimum principal stress appears as compressive stress due to local stress concentration. As the position moves toward center of the Brazilian discs, minimum principal stress gradually changes from positive to negative and gradually turns into tensile stress. Area between the minimum principal stress curve and the intersection of coordinate axis is called tensile stress area. Obviously, ratio $\kappa_{\mathrm{M}}$ has basically no effect on range of this area. According to Fig. 9, the elements exhibit tensile fracture in this area when $\kappa_{\mathrm{M}}=10$. In this region, the stresses in two directions fluctuate greatly due to element damage, which show the largest amplitude in the middle, indicating that the failure first occurs in the middle of disc. However, when $\kappa_{\mathrm{M}}=6$, principal stress in the tensile stress area does not change, but compressive stress fluctuates near the loading platen, which is caused by wedge failure zone in this area. 


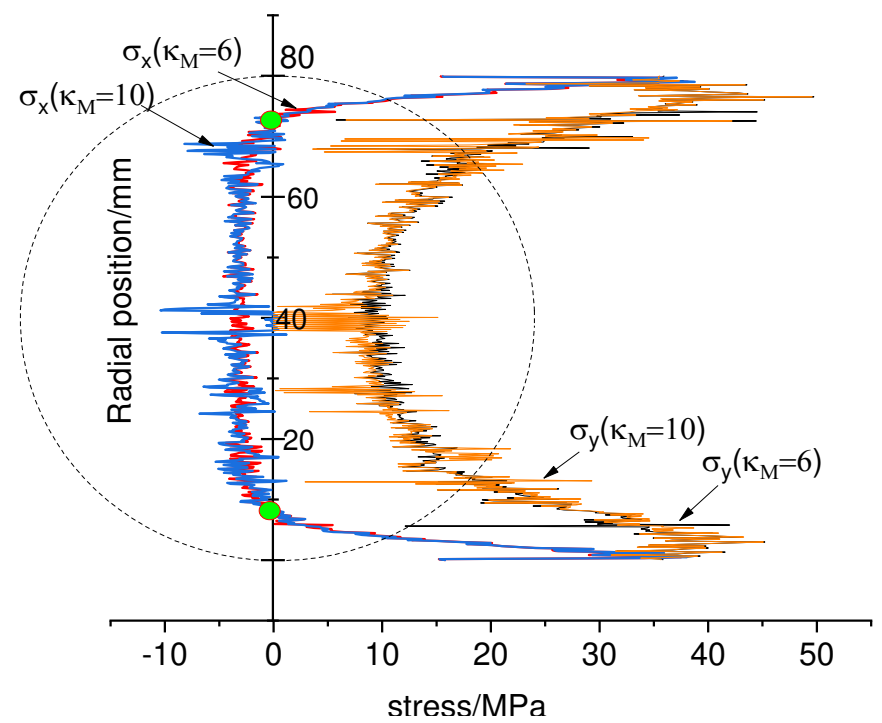

Fig.11 Stress distribution along loading diameter with different compression-tension ratios

\section{Conclusions}

As the most basic and widely used test method for determining tensile strength of rock in geotechnical engineering field, Brazilian disc splitting test has been paid much attention by engineers and researchers. In this paper, a critical criterion is proposed to distinguish tension crack and shear failure of discs under combined tension and compression stress, and numerical verification is also performed. The following are the main conclusions derived from this study:

(1) From theoretical scope, compressive stress at center is exactly three times of tensile stress when the disc is split radially, which is consistent with Griffith strength criterion. It is questionable to use this as criterion of rock tensile failure. Since the compressive-tensile ratio is always a constant of eight no matter what kind of rock it is according to Griffith criterion, and the critical stress state of tensile and shear failure is completely determined by tensile strength, which is not consistent with actual situation.

(2) Compared with parameters of shear strength obtained by the traditional M-C criterion, Griffith criterion and modified M-C criterion based on critical stress state circle, the rock compression-tension ratio obtained by modified M-C criterion is in good agreement with experimental results. Therefore, the region surrounded by critical state circle and uniaxial tensile limit circle can be regarded as critical region for tensile or shear failure under action of combined tensile and compressive stresses.

(3) The results of theoretical and numerical simulation show that if tensile failure occurs in disc, the compression-tension ratio should be greater than 6 . In this range, if disc cracks within the effective diameter (not necessarily at the center of the circle), it can be regarded as an ideal tensile failure. When $\kappa_{\mathrm{M}}<6$, even if the radial crack occurs, it can not be considered as an ideal tensile failure which may contain cracks caused by the expansion of wedge-shaped 
body in the loading area. Therefore, for rock with small compression-tension ratio, there will be a large error between experimental results and actual value.

\section{Data Availability}

The calculation data used to support the findings of this study are included within the article.

\section{Conflicts of Interest}

The authors have no conflicts of interest.

\section{Acknowledgements}

Thanks to the Mechsoft limited company for providing RFPA software during the new crown pneumonia outbreak situation. This work is supported by the National Natural Science Foundation of China and Shandong Province joint Program (U1806209), and National Natural Science Foundation of China (Nos.51774196, 52074169).

\section{References}

Aliha, M. R M . Indirect tensile test assessments for rock materials using 3-D disc-type specimens. Arabian Journal of Geosciences, 2014, 7(11):4757-4766.

Ayatollahi M R , Mahdavi E , Alborzi M J , et al. Stress Intensity Factors of Semi-Circular Bend Specimens with Straight-Through and Chevron Notches. Rock Mechanics and Rock Engineering, 2016, 49(4):1161-1172.

Chau K T, Wei X X. A new analytic solution for the diametral point load strength test on finite solid circular cylinders. International Journal of Solids and Structures, 2001, 38: $1459-$ 1481 .

Han L, He Y, Zhang H . Study of rock splitting failure based on griffith strength theory. International Journal of Rock Mechanics and Mining Sciences, 2016, 83:116-121.

ISRM. Suggested methods for determining tensilestrength of rock materials. International Journal of Rock Mechanics Mining Science \& Geomechanics Abstracts., 1978, 15(1): 99-103.

J, Claesson, and, B, \& Bohloli. (2002). Brazilianian test: stress field and tensile strength of anisotropic rocks using an analytical solution. International Journal of Rock Mechanics and Mining Sciences.

Kourkoulis S K, Markides C F, Chatzistergos P E. The standardized Brazilianian disc test as a contact problem. International Journal of Rock Mechanics and Mining Sciences, 2013, 57:132-141.

Li Guangwei. Mechanical properties of rock mass. Beijing: China Coal Industry Publishing House, 1983.

Li Wei, Xie Heping, Wang Qizhi. Experimental study for dynamic tensile strength and elastic modulus of marble using SHPB. Journal of Experimental Mechanics, 2005, 20(2): 200-206. 
Lin H, Xiong W, Xiong Z , et al. Three-dimensional effects in a flattened Brazilianian disk test. International Journal of Rock Mechanics and Mining Sciences, 2015, 74:10-14.

Lyu XZ, Zhao ZH, Wang XJ, Wang WM. Study on the Permeability of Weakly Cemented Sandstones. Geofluids, vol. 2019, Article ID 8310128, 14 pages, 2019.

Markides C F , Pasiou E D , Kourkoulis S K. The bi-material circular disc compressed between the jaws of the ISRM standardized apparatus for the Brazilianian test. Procedia Structural Integrity, 2016, 2:2881-2888.

Perras M A, Diederichs M S . A Review of the Tensile Strength of Rock: Concepts and Testing. Geotechnical and Geological Engineering, 2014, 32(2):525-546.

Serati M, Alehossein H, Williams D J . 3D Elastic Solutions for Laterally Loaded Discs: Generalised Brazilianian and Point Load Tests. Rock Mechanics and Rock Engineering, 2014, 47(4):1087-1101.

Tavallali A, Vervoort A. Effect of layer orientation on the failure of layered sandstone under Brazilianian test conditions. International Journal of Rock Mechanics \& Mining Sciences, 2010, 47(2): 313-322.

Tao Jinan. Discussion on the application scope and critical stress state of Mohr Coulomb criterion. Chinese Journal of Geotechnical Engineering, 1990,12(5):76-83.

Wang Huiwen, Li Jiangteng, Gao Jichao, et al. Tensile strength of slates under Brazilianian splitting test in dry and saturated condition. Journal of Central South University (Science and Technology),2017,48(4):1044-1048.

Wang S Y, Sloan S W, Tang C A. Three-Dimensional Numerical Investigations of the Failure Mechanism of a Rock Disc with a Central or Eccentric Hole. Rock Mechanics and Rock Engineering, 2013, 47(6):2117-2137.

Wu Qiu-hong, Zhao Fu-jun, Li Xi-bing, et al. Mechanical properties of ring specimens of sandstone subjected to diametral compression. Rock and Soil Mechanics, 2018,39(11):39693975.

Yangtze River Scientific Research Institute. SL 264-2001 Specifications for rock tests in water conservancy and hydroelectric engineering. Beijing: China Water Power Press, 2001.

You Mingqing, Chen Xianglei, SU Chengdong. Brazilianian splitting strengths of discs and rings of rocks in dry and saturated conditions. Chinese Journal of Rock Mechanics and Engineering, 2011, 30(3):464-472.

Yu Maohong. Advances in strength theories for materials under complex stress state in the 20th century. Advances in Mechanics, 2004, 34(25):529-560.

$\mathrm{Yu}$ Yong. Questioning the validity of the Brazilianian test for determining tensile strength of rocks. Chinese Journal of Rock Mechanics and Engineering, 2005,24(7):1150-1157.

Yu J , Shang X, Wu P. Influence of pressure distribution and friction on determining mechanical properties in the Brazilianian test: Theory and experiment. International Journal of Solids and Structures, 2018.

Yuan R, Shen B . Numerical modelling of the contact condition of a Brazilianian disk test and its influence on the tensile strength of rock. International Journal of Rock Mechanics and Mining Sciences, 2017, 93:54-65.

Zhao Z Z ,Zhang M Z,Ma Q, et al. Deviation Effect of Coaxiality on the Rock Brazilianian Split, Advances in Mathematical Physics, Volume 2020, Article ID 5782457, 
https://doi.org/10.1155/2020/57824572020.

Zhang Lei , LIU Bao-guo. A comparison study of rock strength criteria considering tensile strength. Engineering Mechanics. 2016,33(11):201-207.

Zhu Wan-cheng, Tang Chun-an, Huang Zhi-ping, Pang Ming-zhang. Numerical simulation on splitting failure mode of rock under static and dynamic loadings. Chinese Journal of Rock Mechanics and Engineering,2005, 24(1):1-7. 
Figures

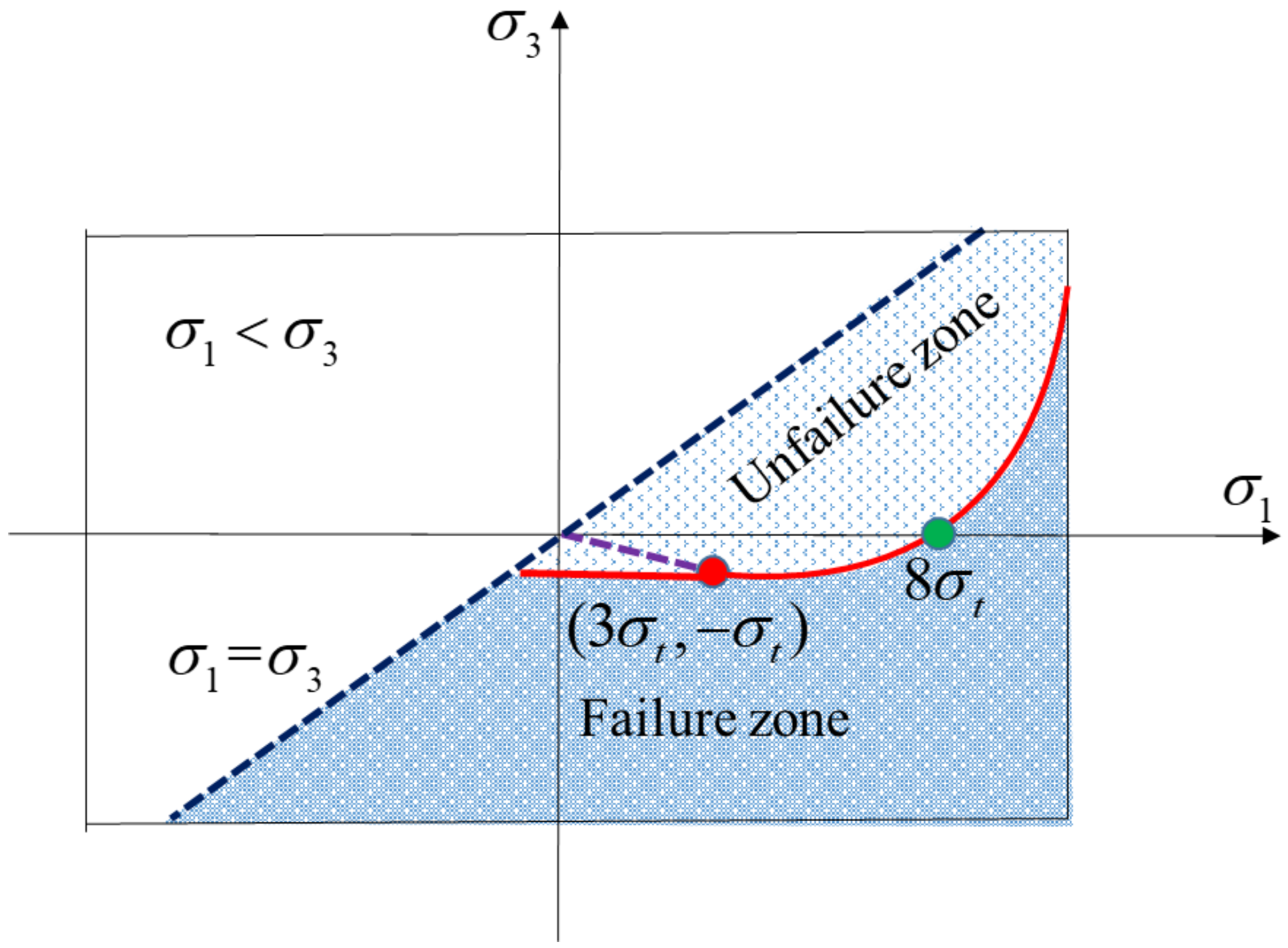

Figure 1

Griffith strength criterion 


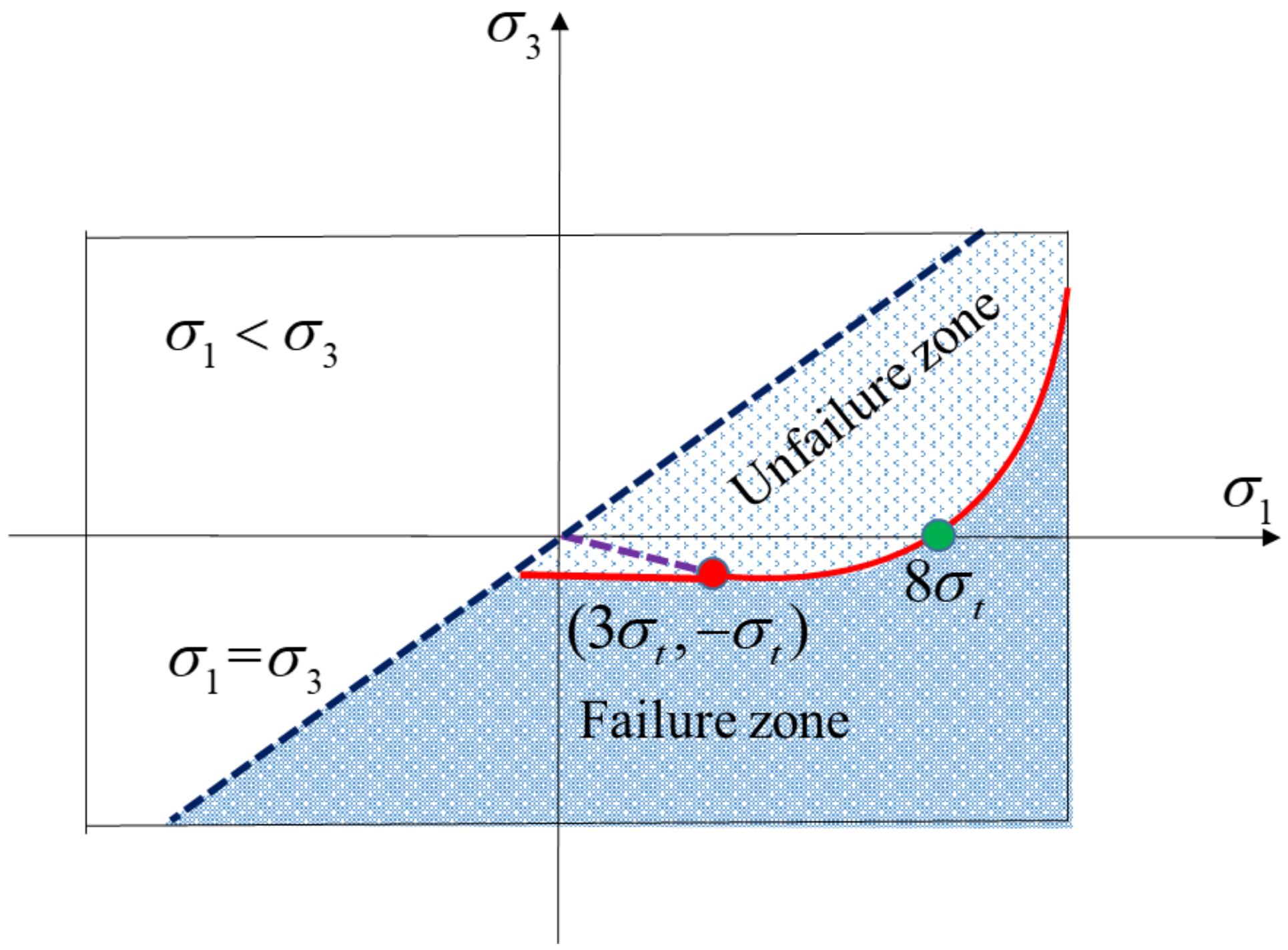

Figure 1

Griffith strength criterion 


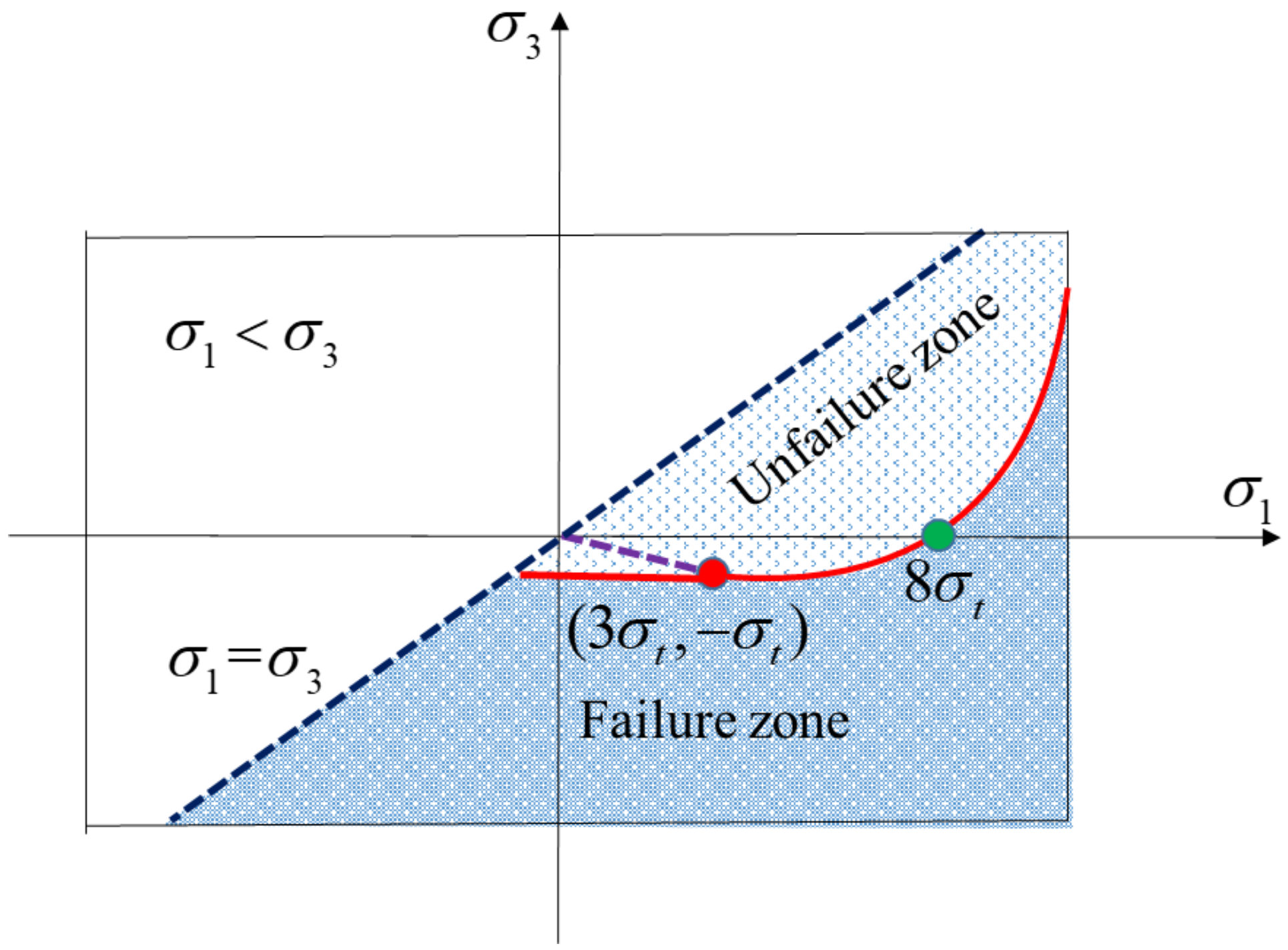

Figure 1

Griffith strength criterion 


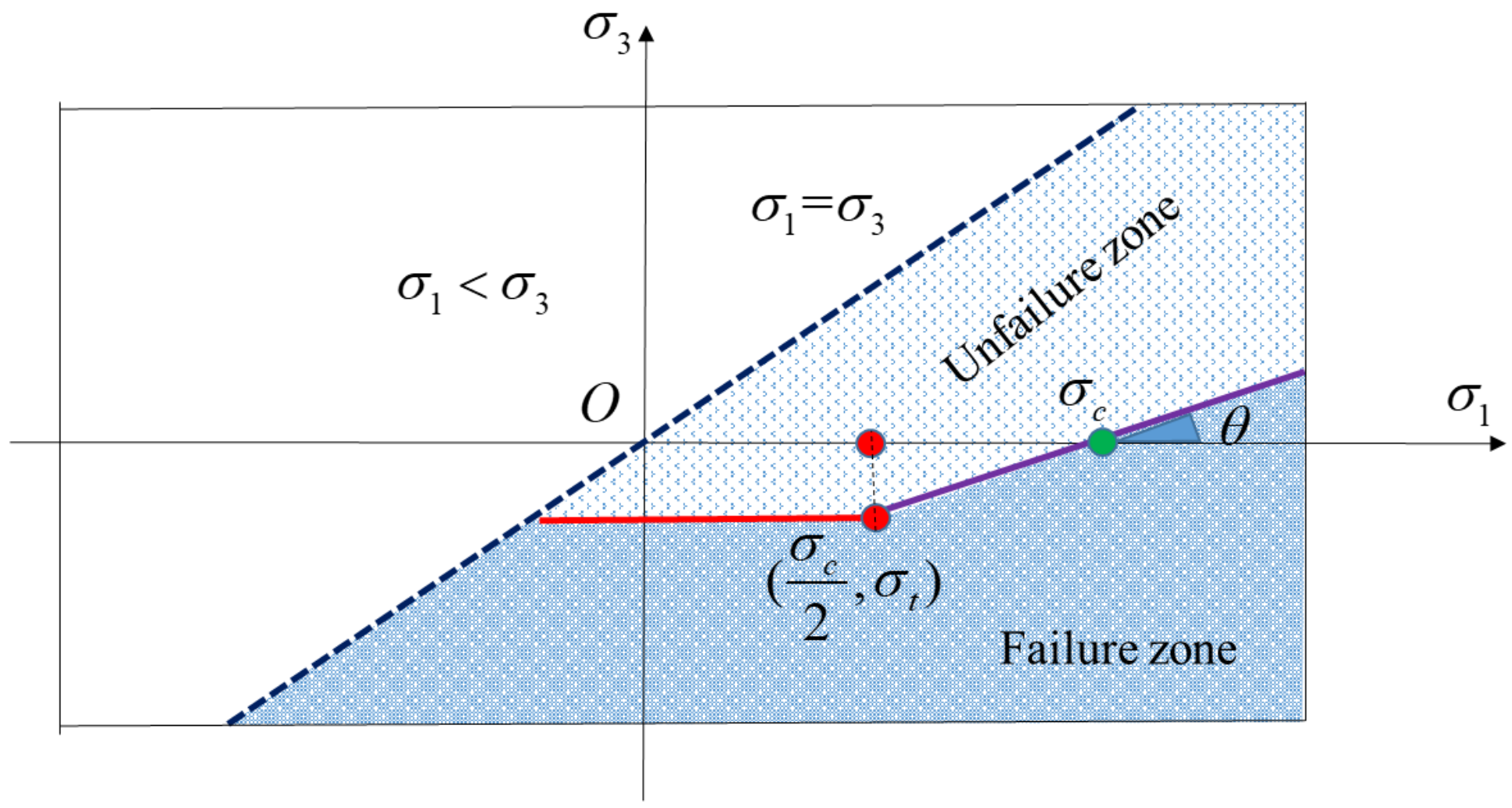

Figure 2

Modified Mohr-coulomb criterion

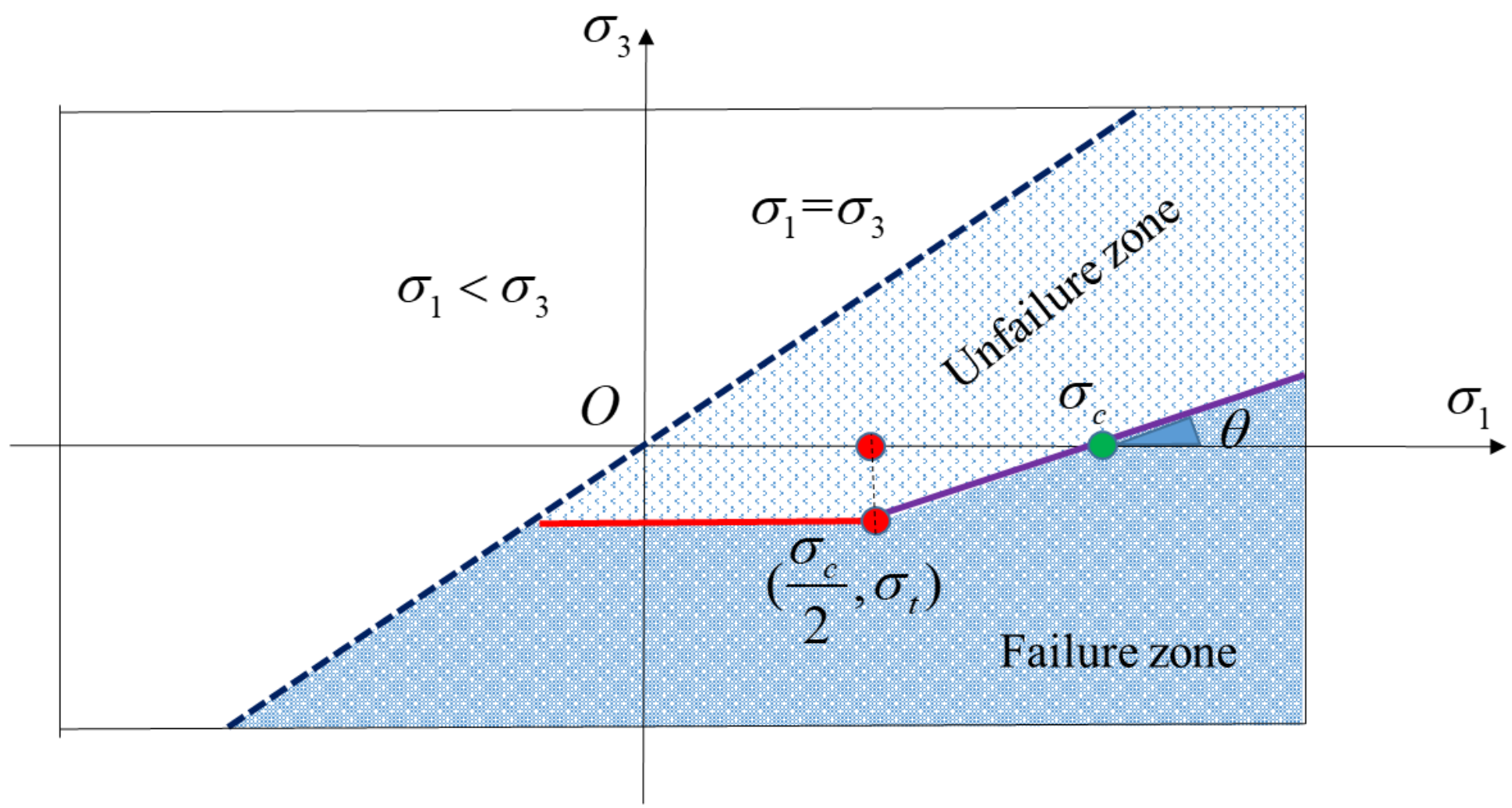

Figure 2 


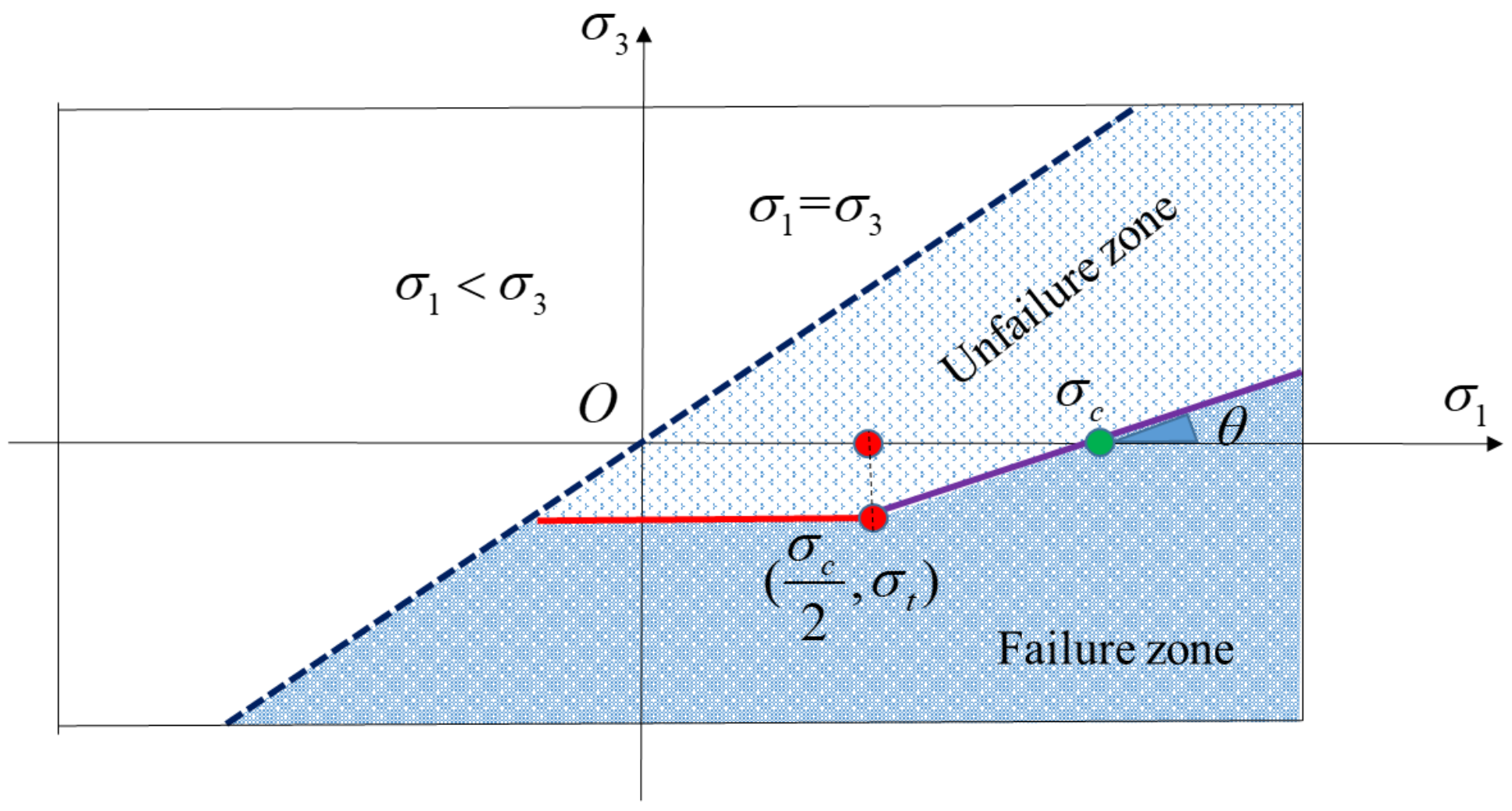

Figure 2

Modified Mohr-coulomb criterion

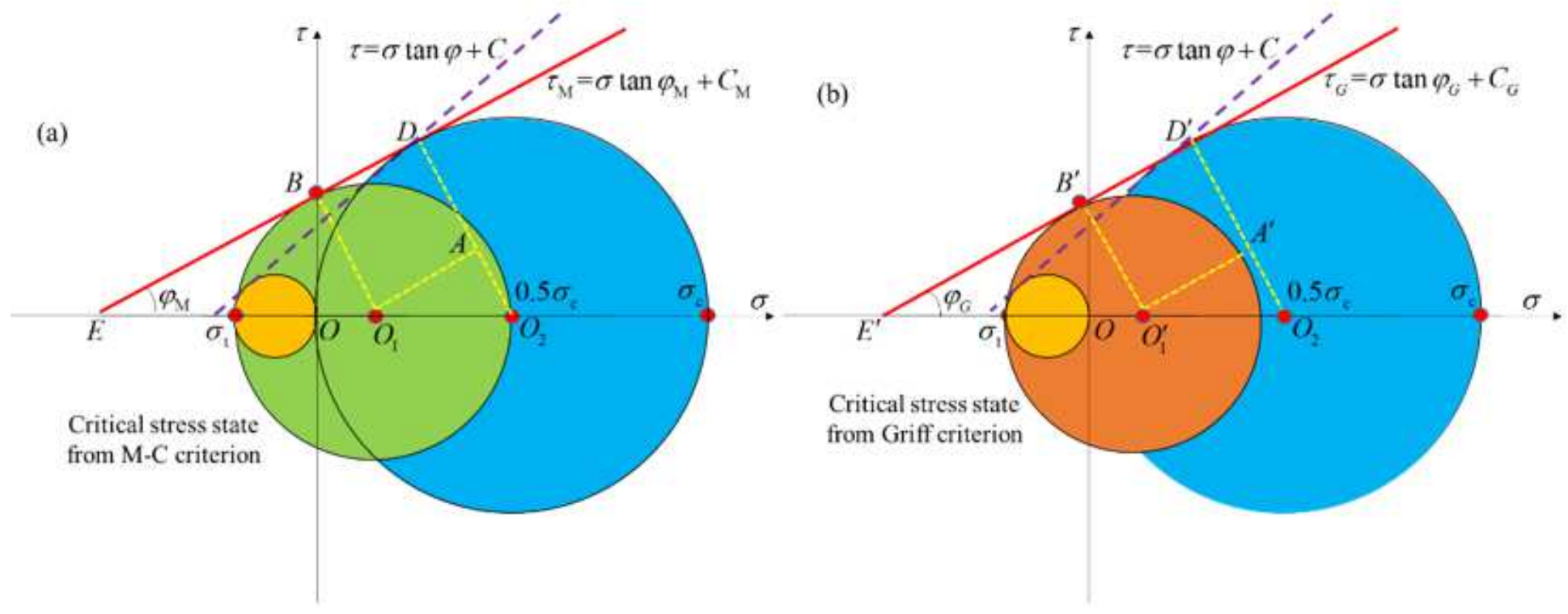

\section{Figure 3}

Determination of strength parameters using stress circles of critical stress state 


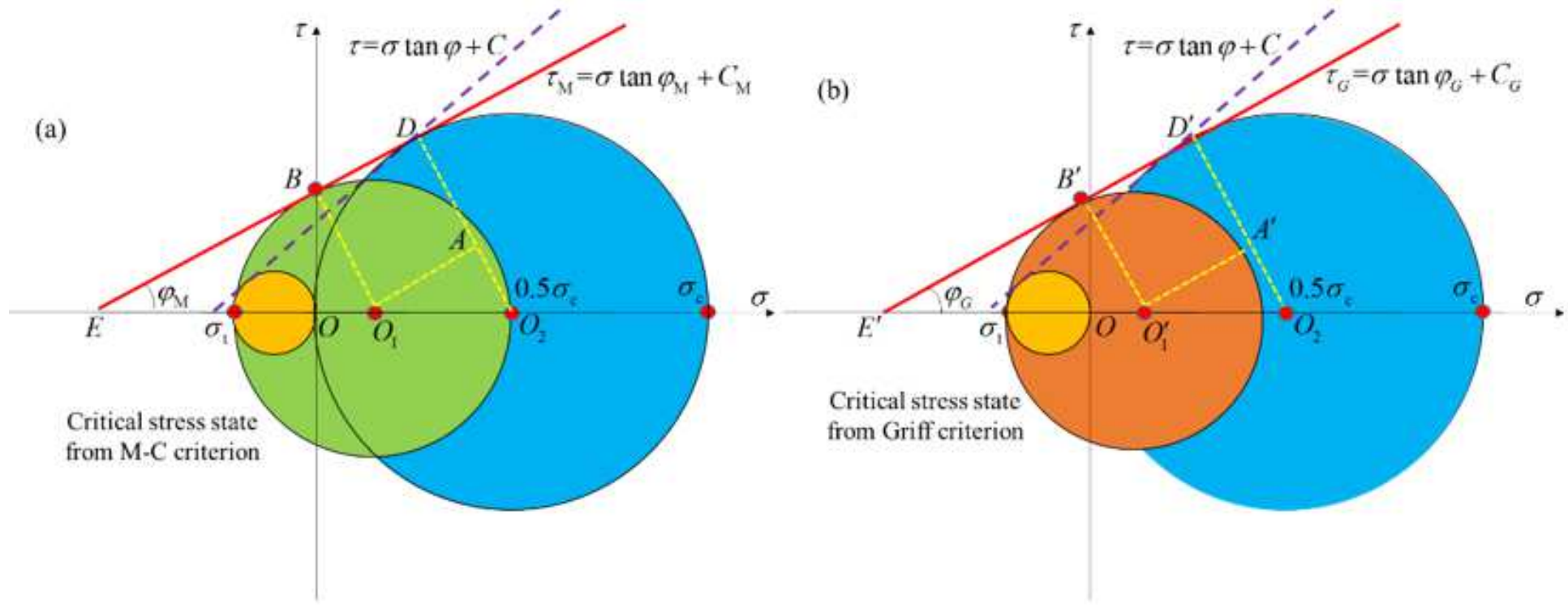

\section{Figure 3}

Determination of strength parameters using stress circles of critical stress state

(a)

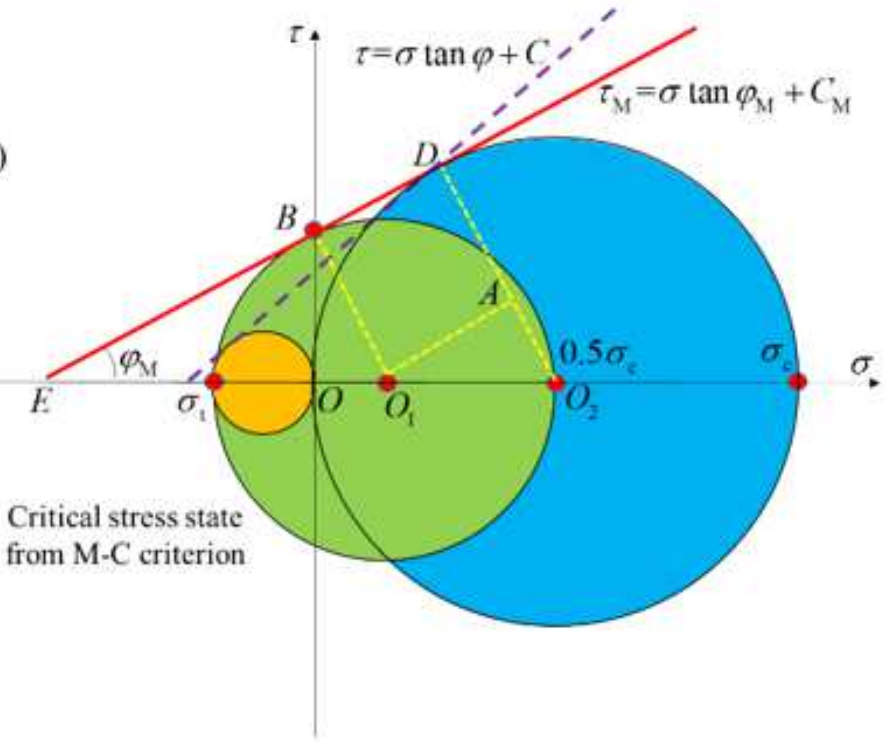

(b)

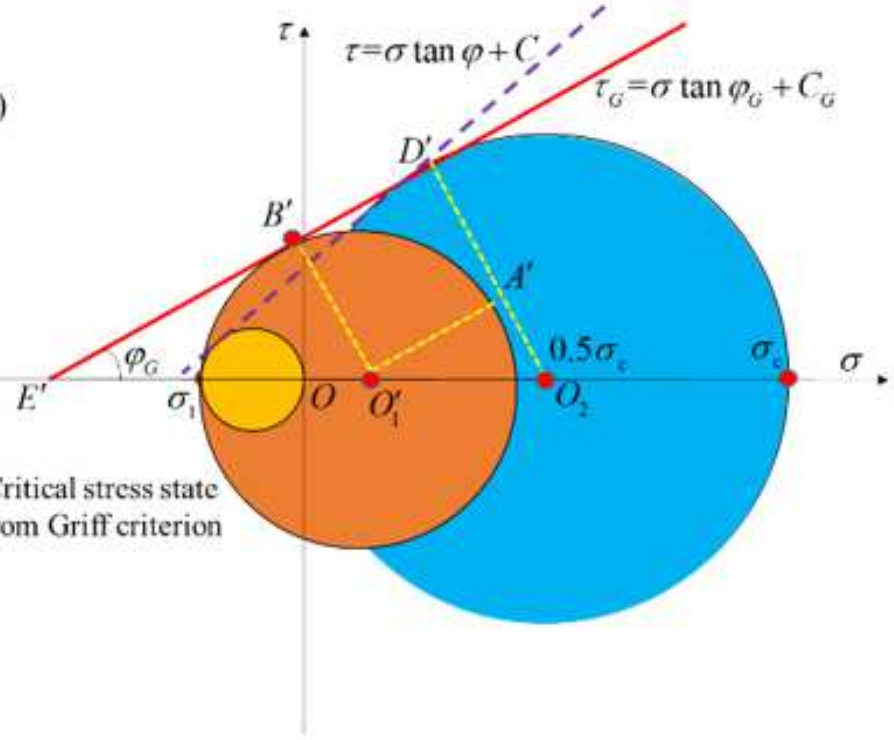

\section{Figure 3}

Determination of strength parameters using stress circles of critical stress state 


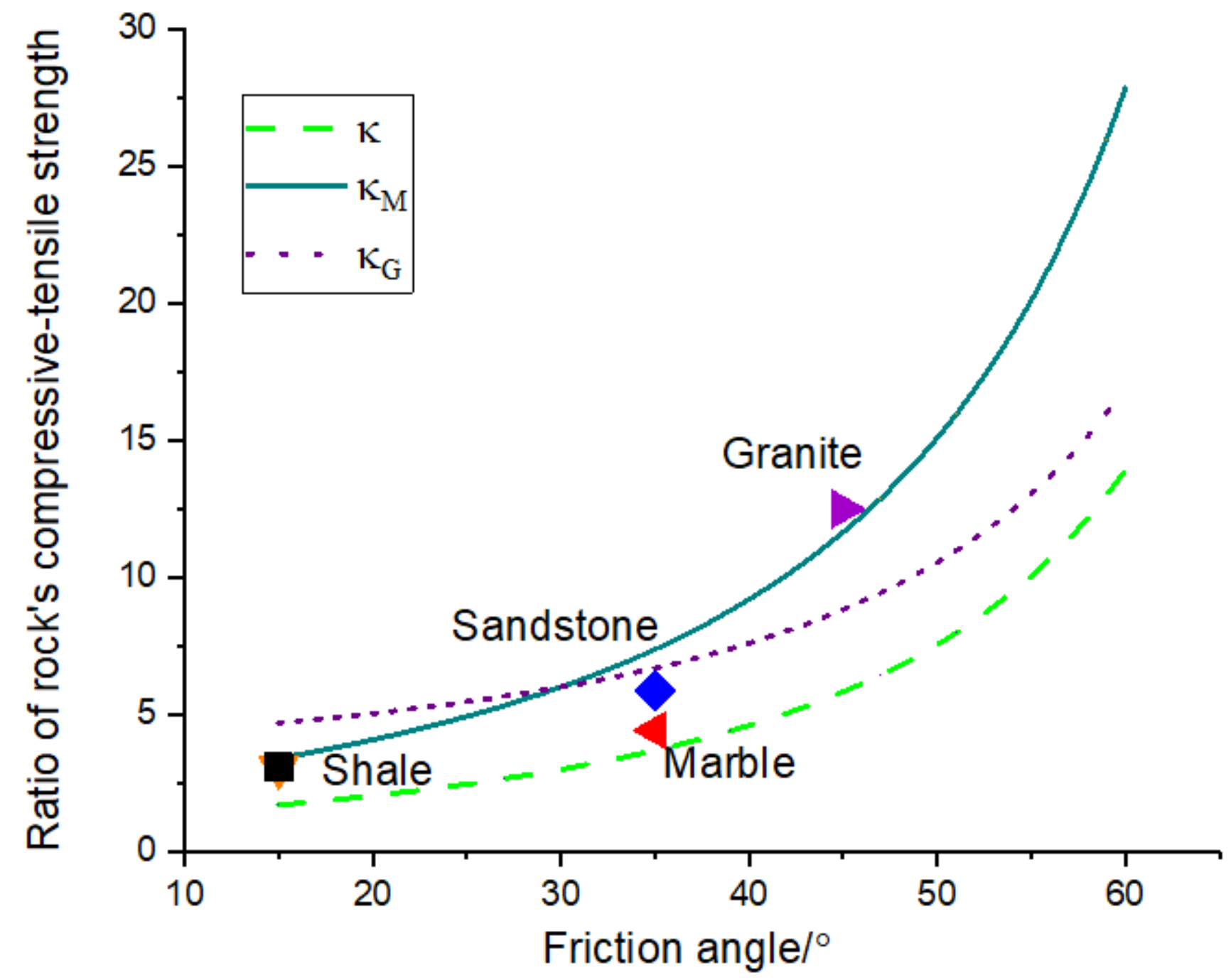

Figure 4

Comparison between theoretical and experimental results 


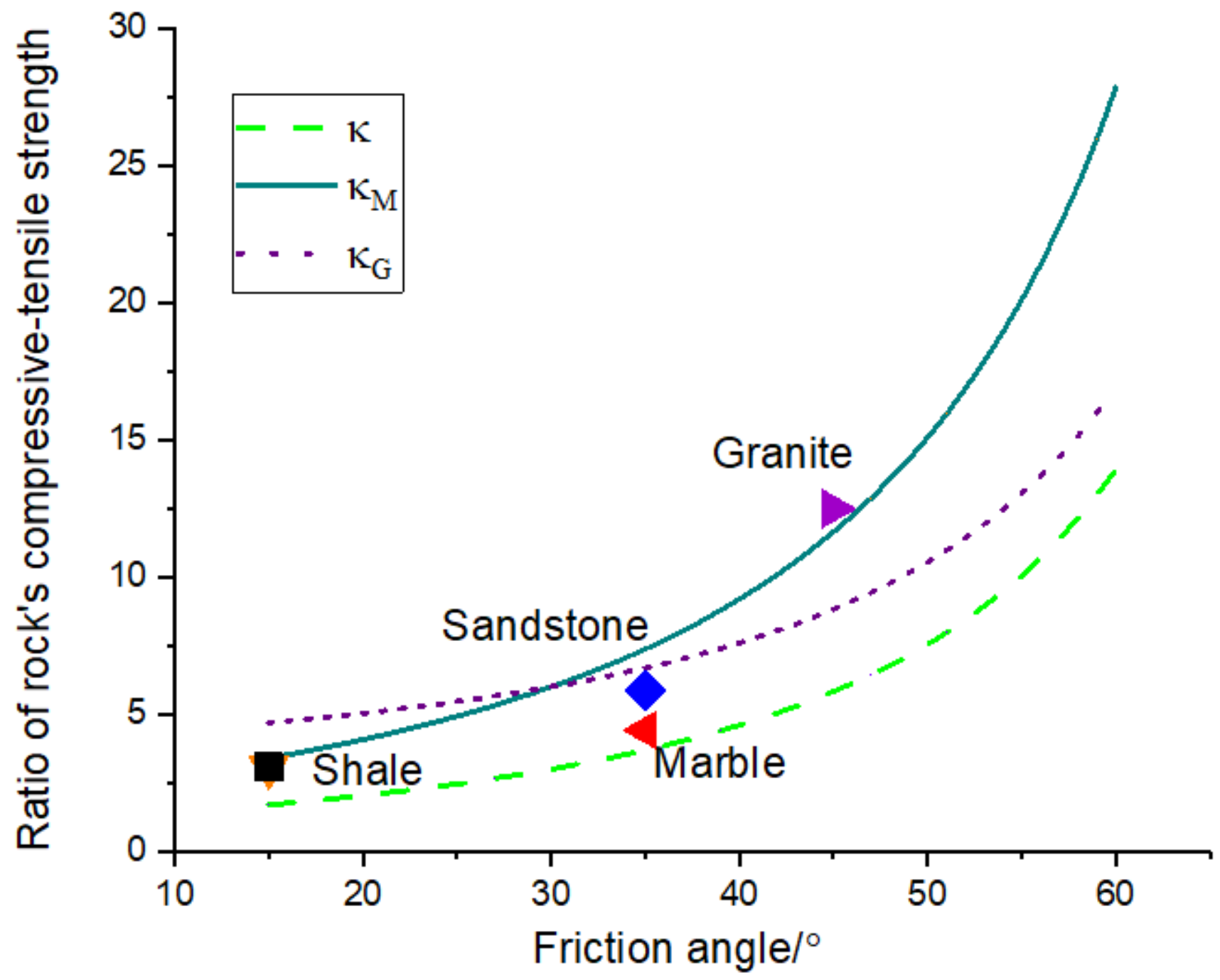

Figure 4

Comparison between theoretical and experimental results 


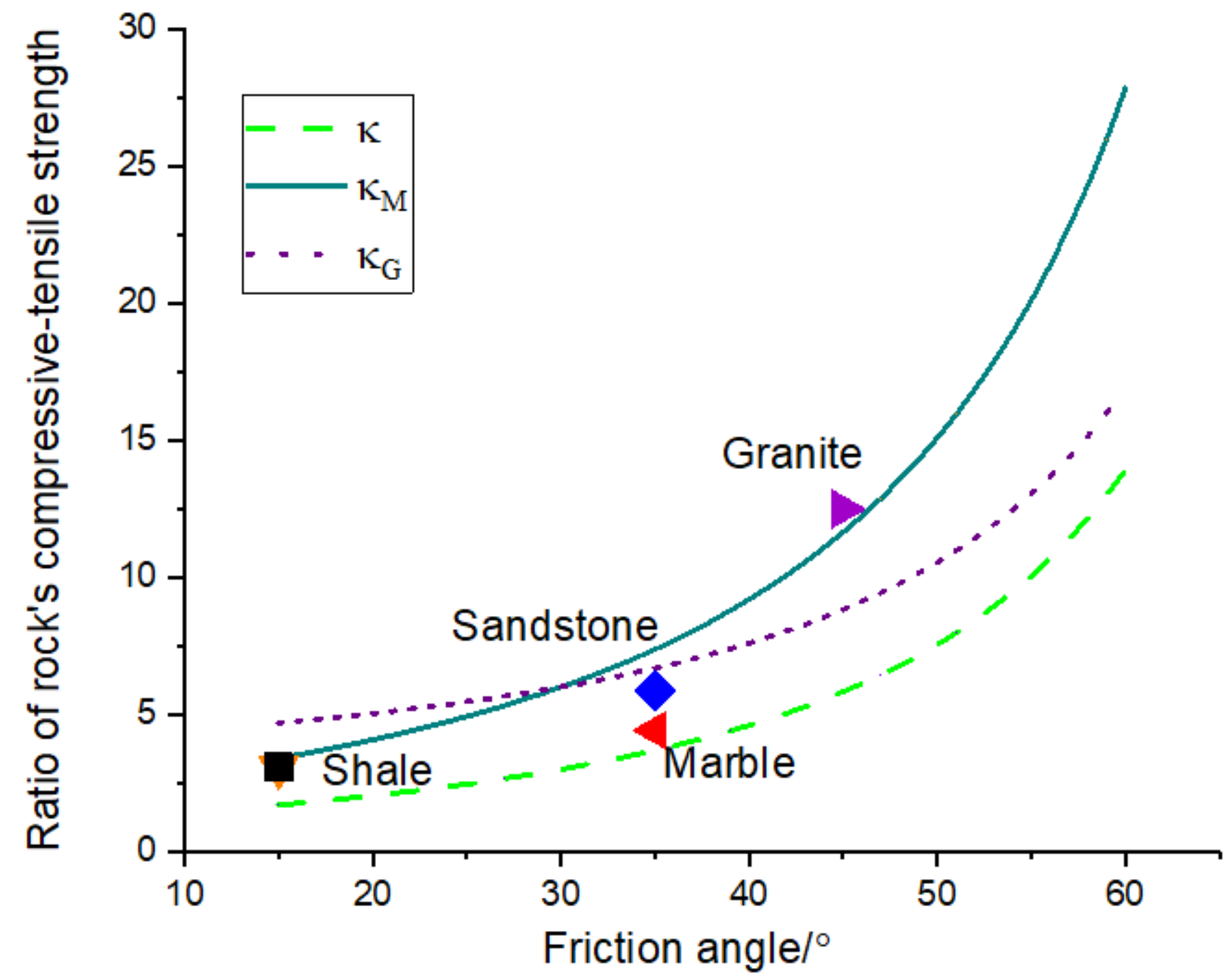

Figure 4

Comparison between theoretical and experimental results 

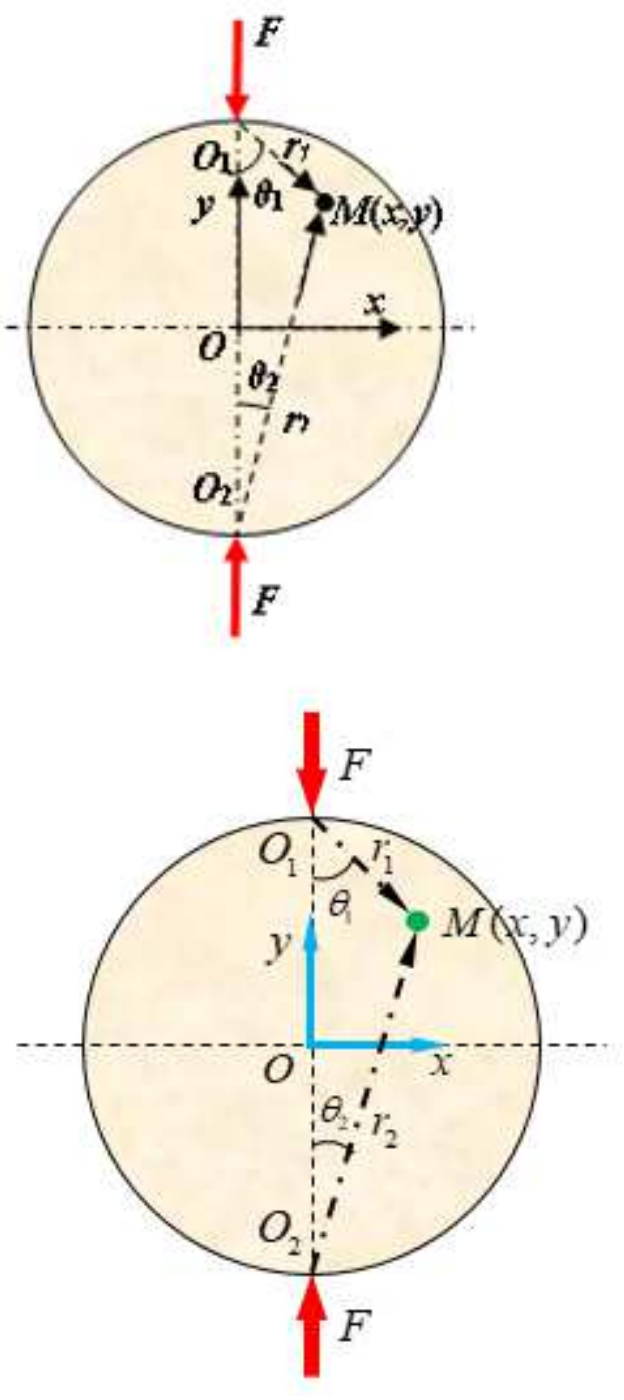

Figure 5

Brazilian disc under radial splitting 

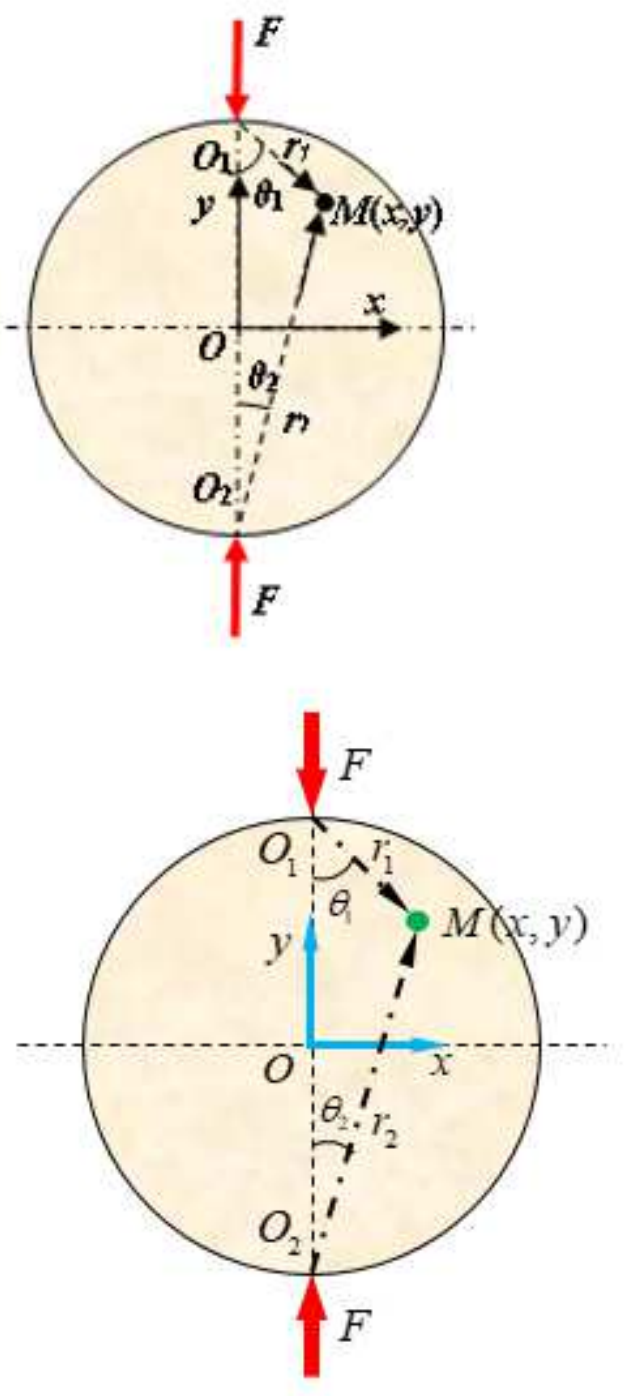

Figure 5

Brazilian disc under radial splitting 

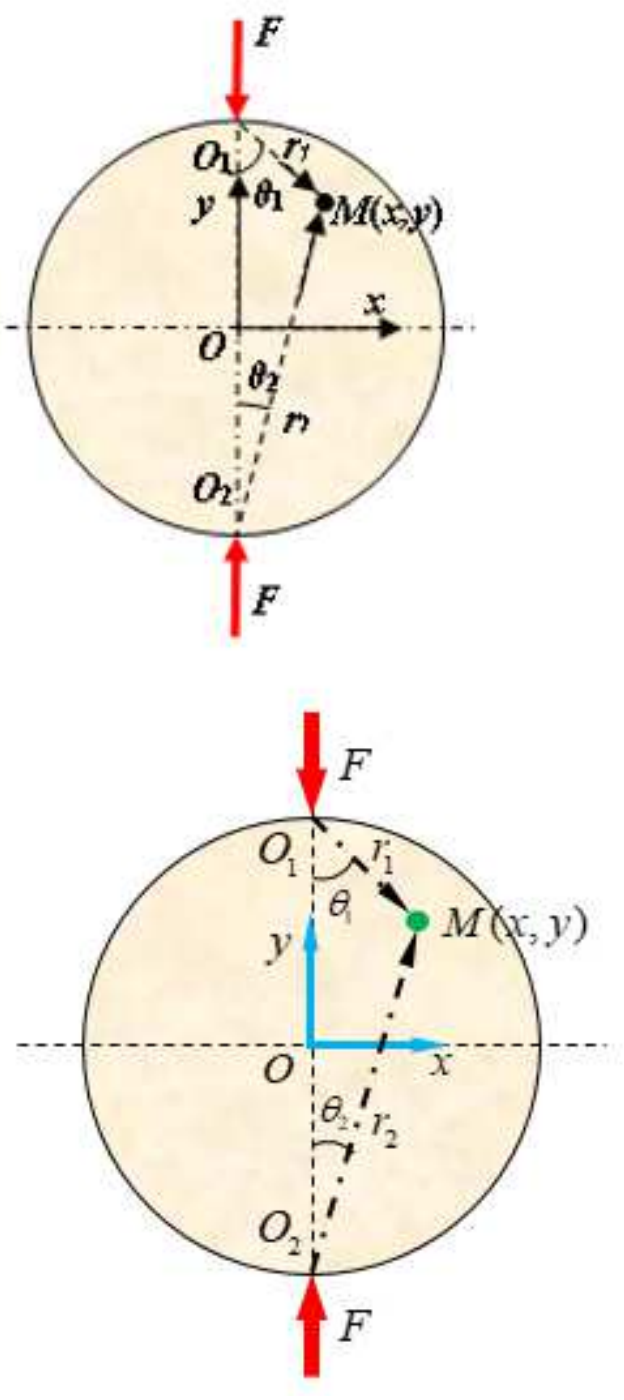

Figure 5

Brazilian disc under radial splitting 


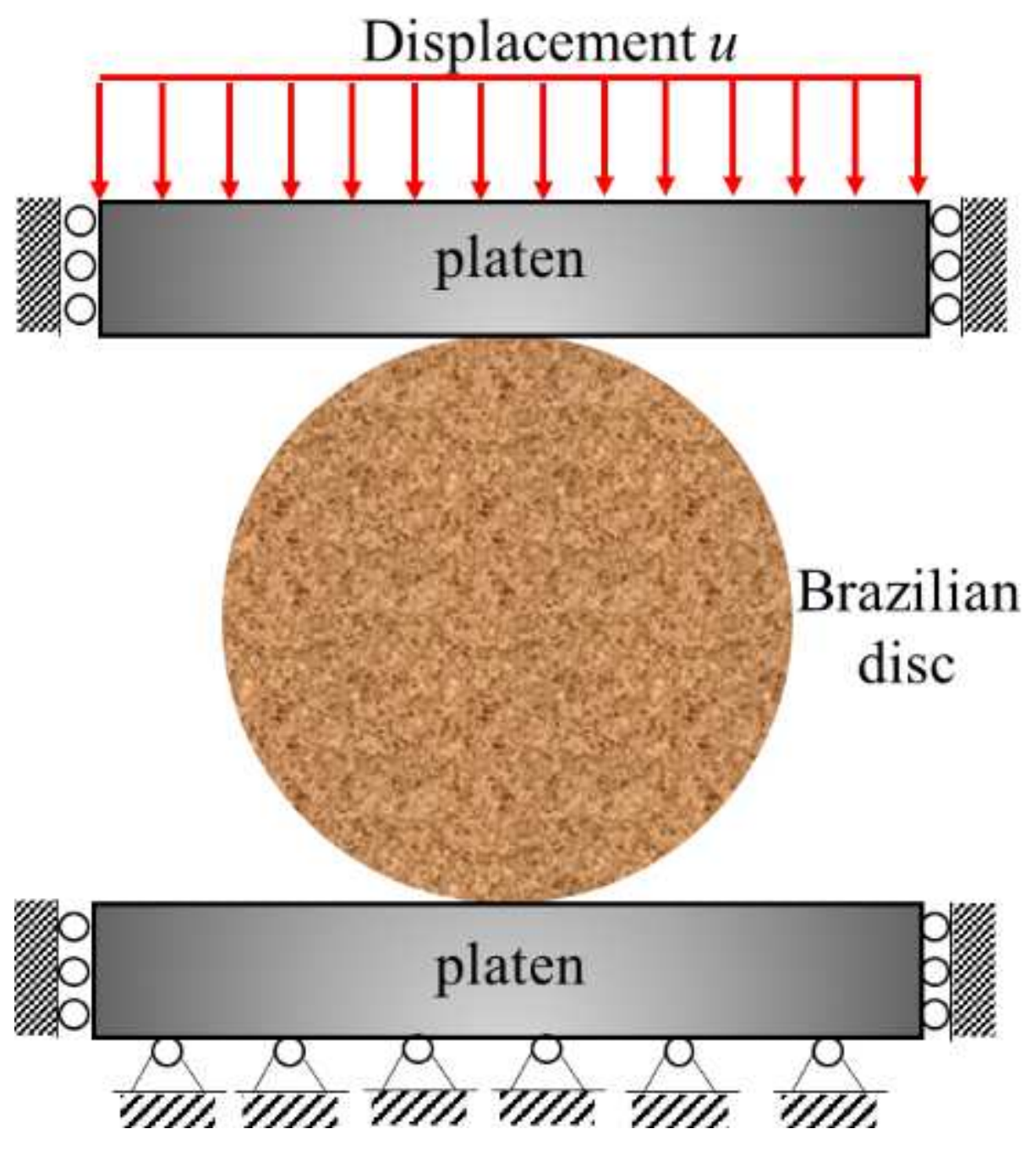

Figure 6

Model of Brazilian disc under radial splitting 


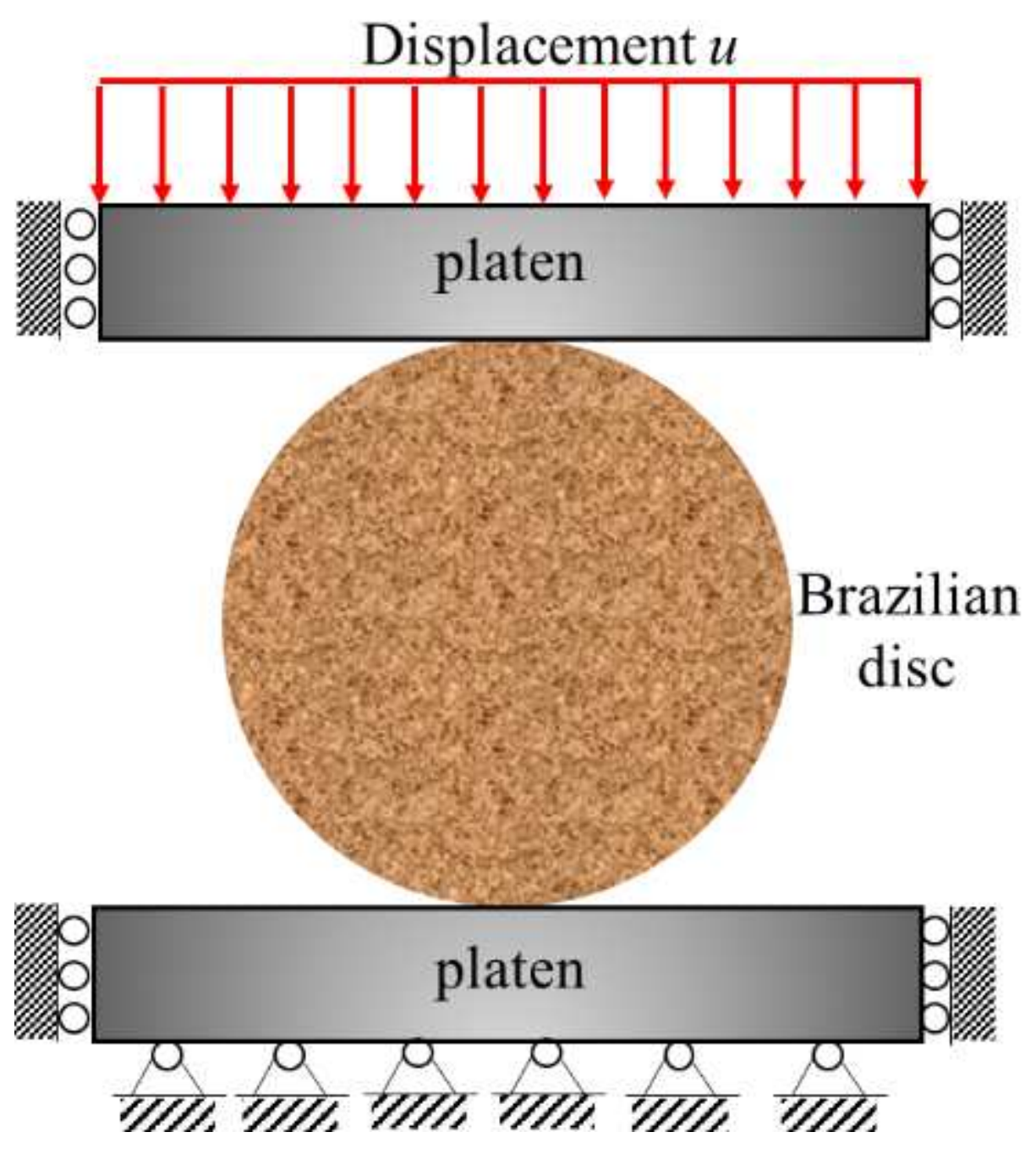

Figure 6

Model of Brazilian disc under radial splitting 


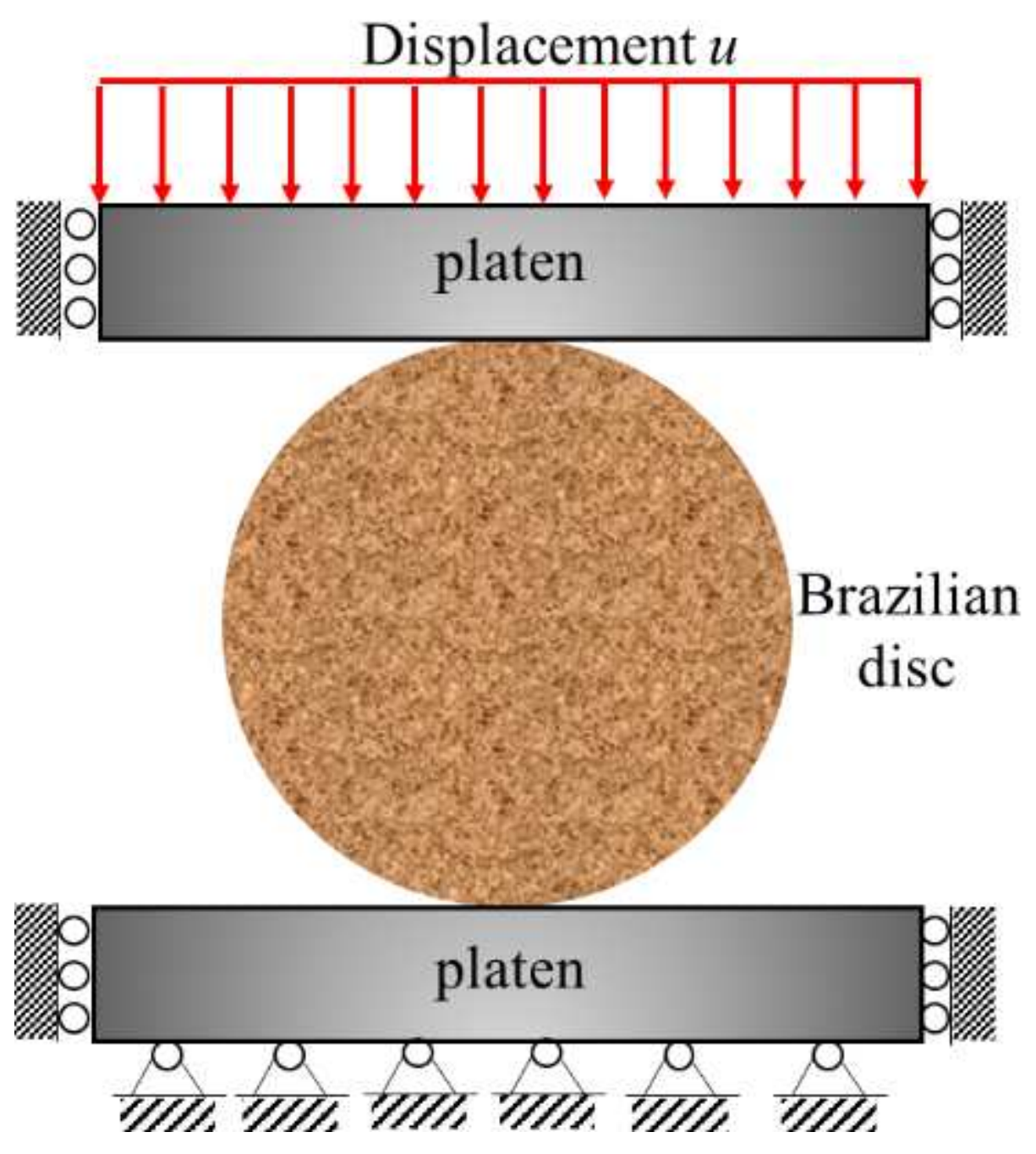

Figure 6

Model of Brazilian disc under radial splitting 


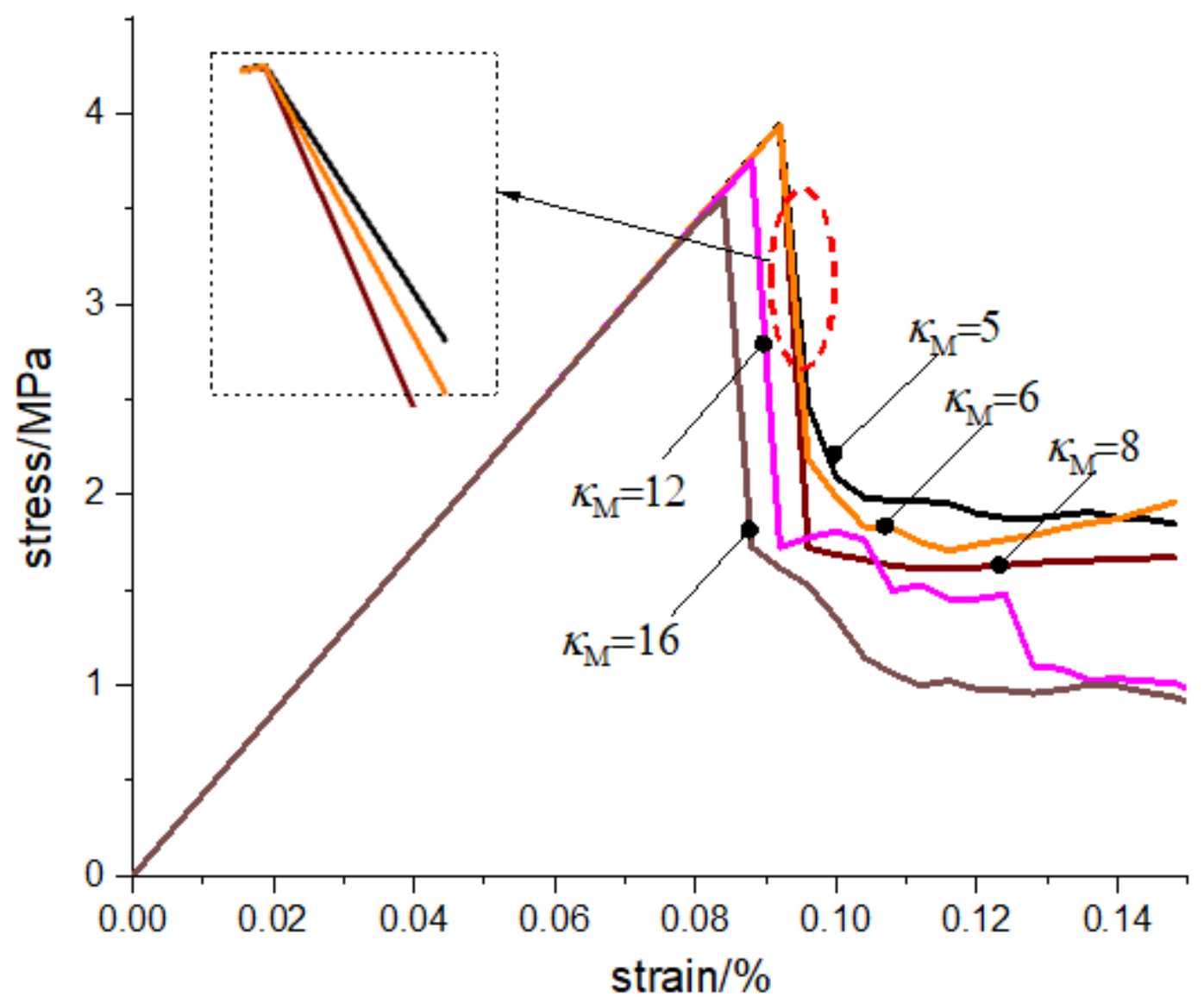

Figure 7

Stress-strain curves of Brazilian discs with different compression-tension ratios 


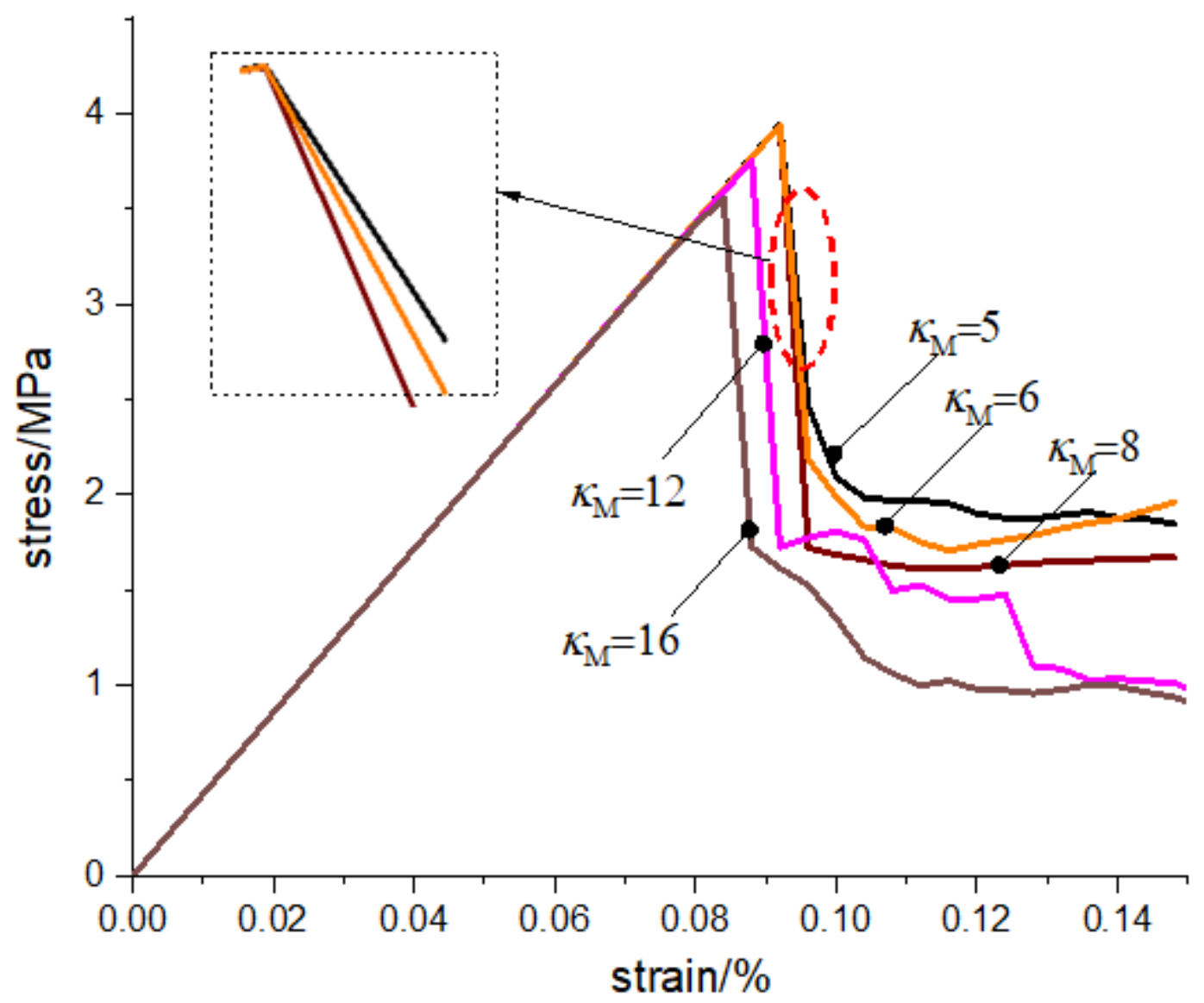

Figure 7

Stress-strain curves of Brazilian discs with different compression-tension ratios 


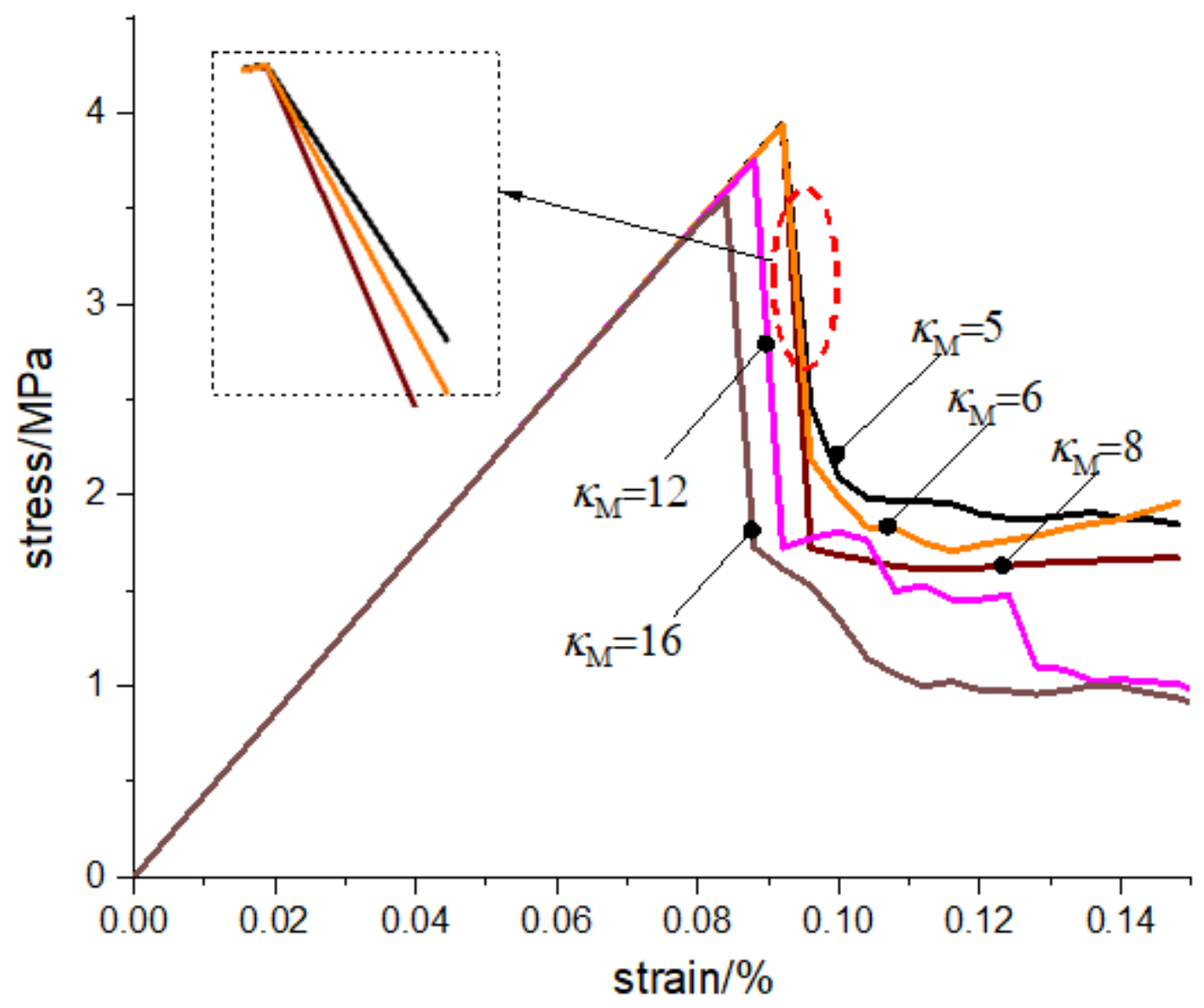

Figure 7

Stress-strain curves of Brazilian discs with different compression-tension ratios

\begin{tabular}{|c|c|c|c|c|}
\hline \multicolumn{5}{|c|}{$\begin{array}{c}\text { Damaged } \\
\text { zone }\end{array}$} \\
\hline \multicolumn{5}{|l|}{$\mathrm{AE}$} \\
\hline & $\kappa_{\mathrm{M}}=5$ & $\kappa_{\mathrm{M}}=6$ & $\kappa_{\mathrm{M}}=8$ & $\kappa_{\mathrm{M}}=10$ \\
\hline
\end{tabular}

Figure 8 
Failure characteristics and AE of Brazilian discs with different KM

\begin{tabular}{|c|c|c|c|c|}
\hline \multicolumn{5}{|l|}{$\begin{array}{c}\text { Damaged } \\
\text { zone }\end{array}$} \\
\hline \multicolumn{5}{|l|}{$\mathrm{AE}$} \\
\hline 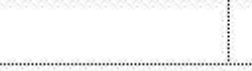 & $\kappa_{\mathrm{M}}=5$ & $\kappa_{\mathrm{M}}=6$ & $\kappa_{\mathrm{M}}=8$ & $\kappa_{\mathrm{M}}=10$ \\
\hline
\end{tabular}

\section{Figure 8}

Failure characteristics and AE of Brazilian discs with different KM

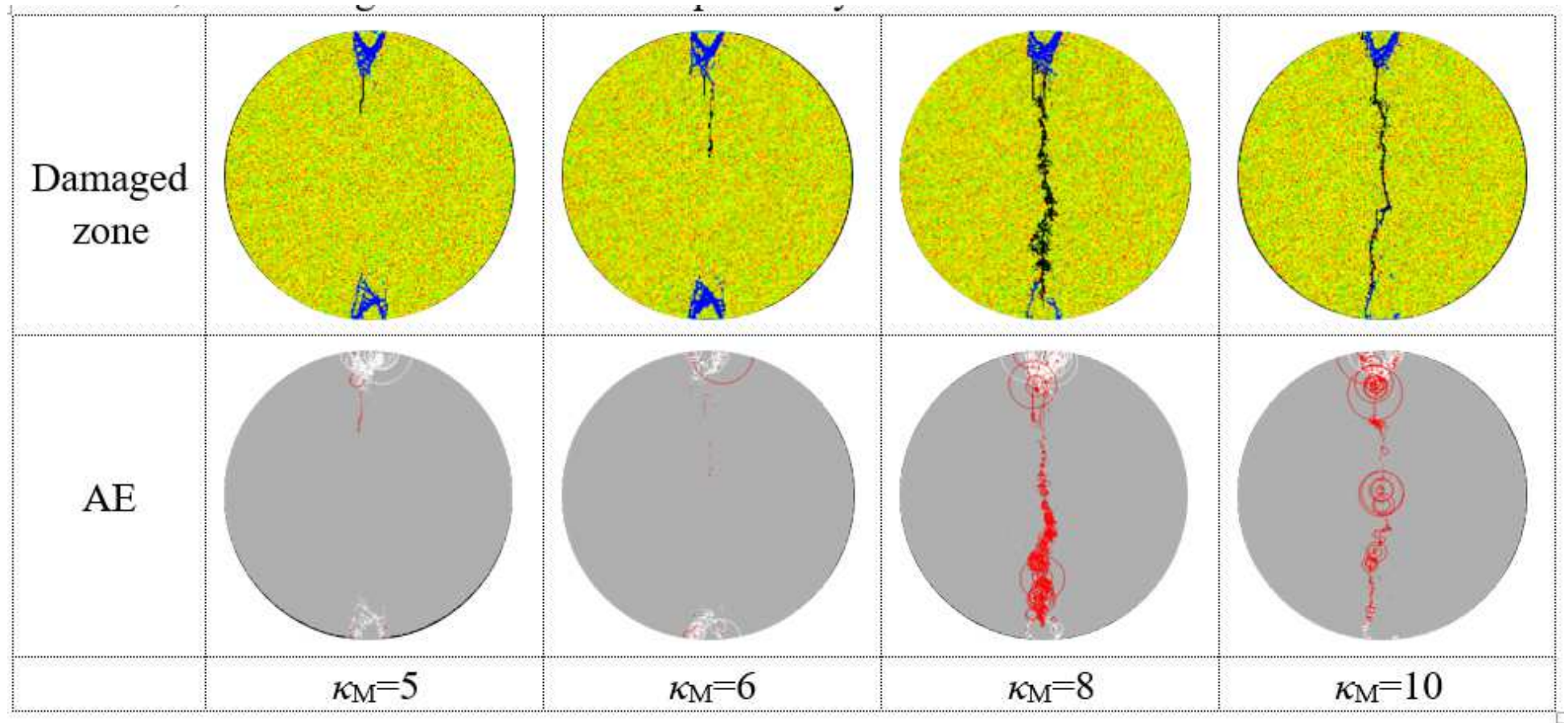

Figure 8

Failure characteristics and AE of Brazilian discs with different KM 

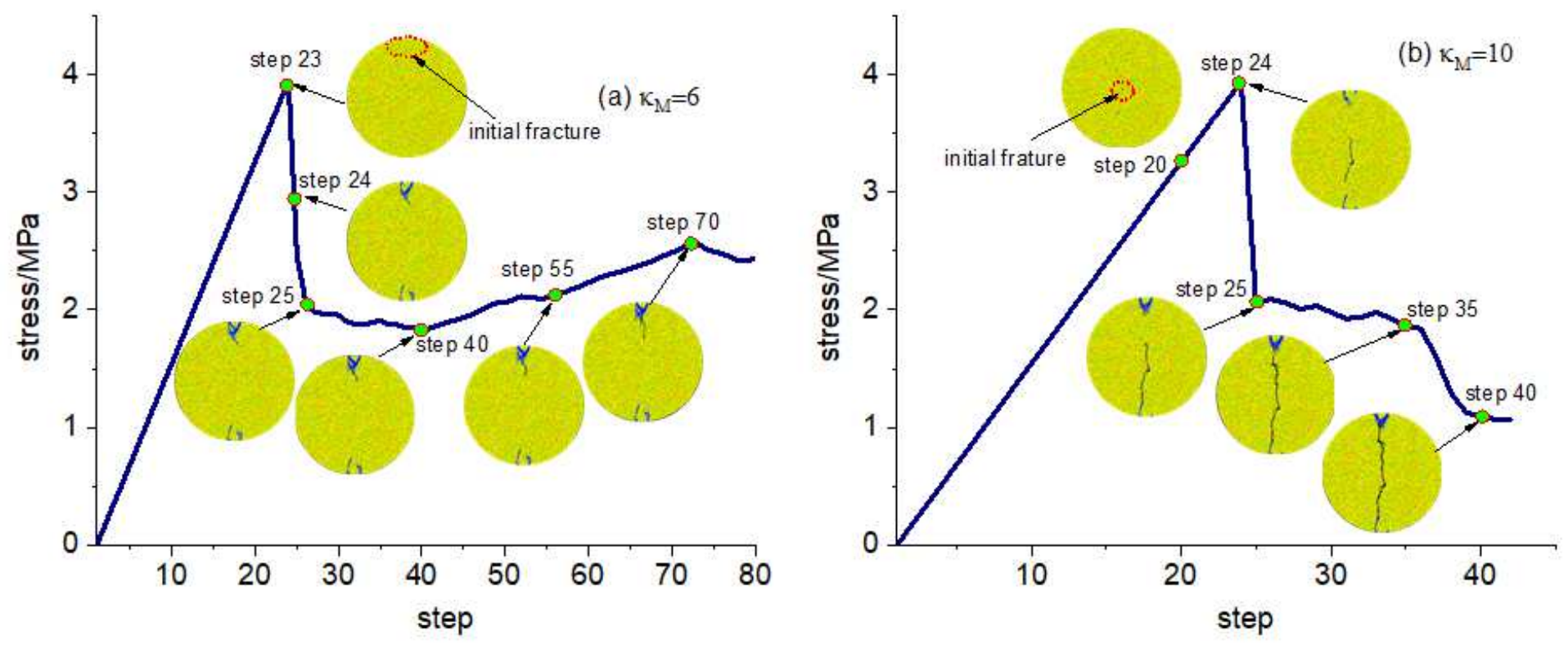

Figure 9

Effect of compression-tension ratios on the failure evolution process of Brazilian discs
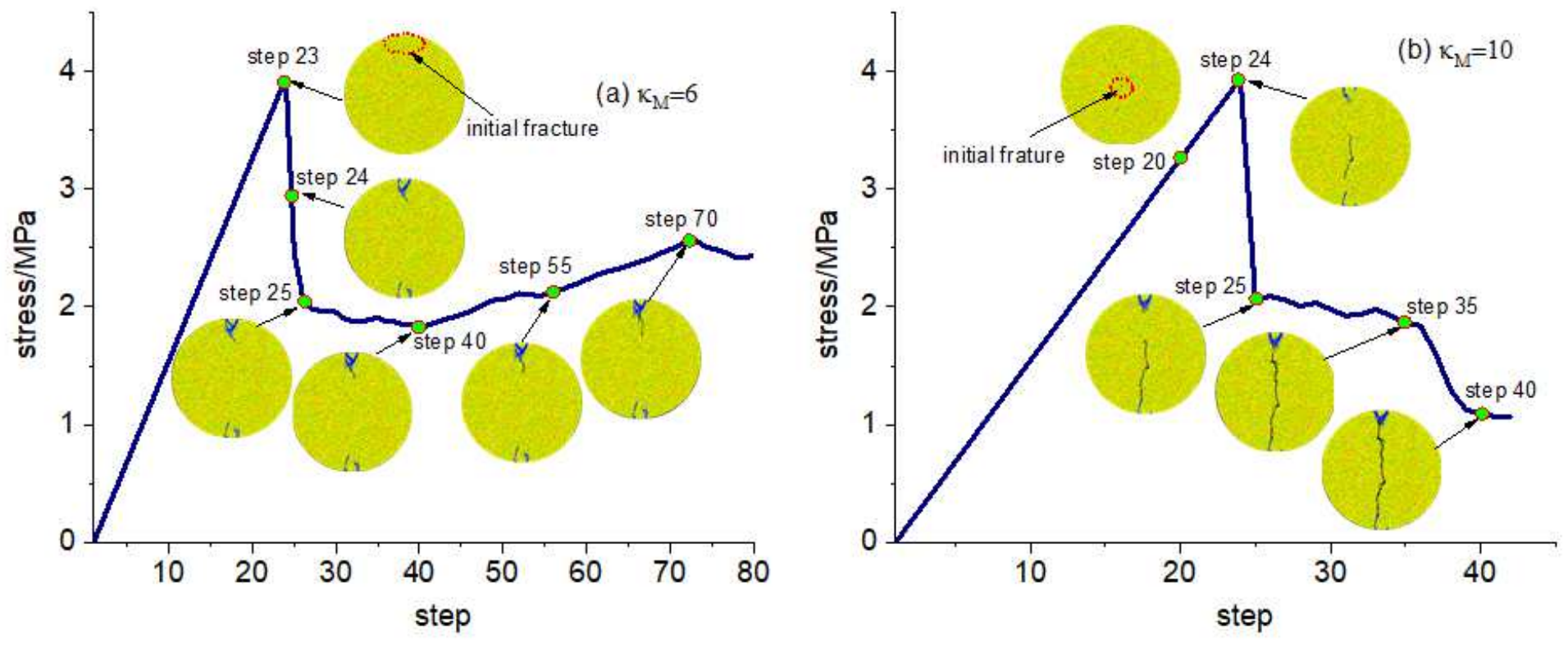

Figure 9

Effect of compression-tension ratios on the failure evolution process of Brazilian discs 

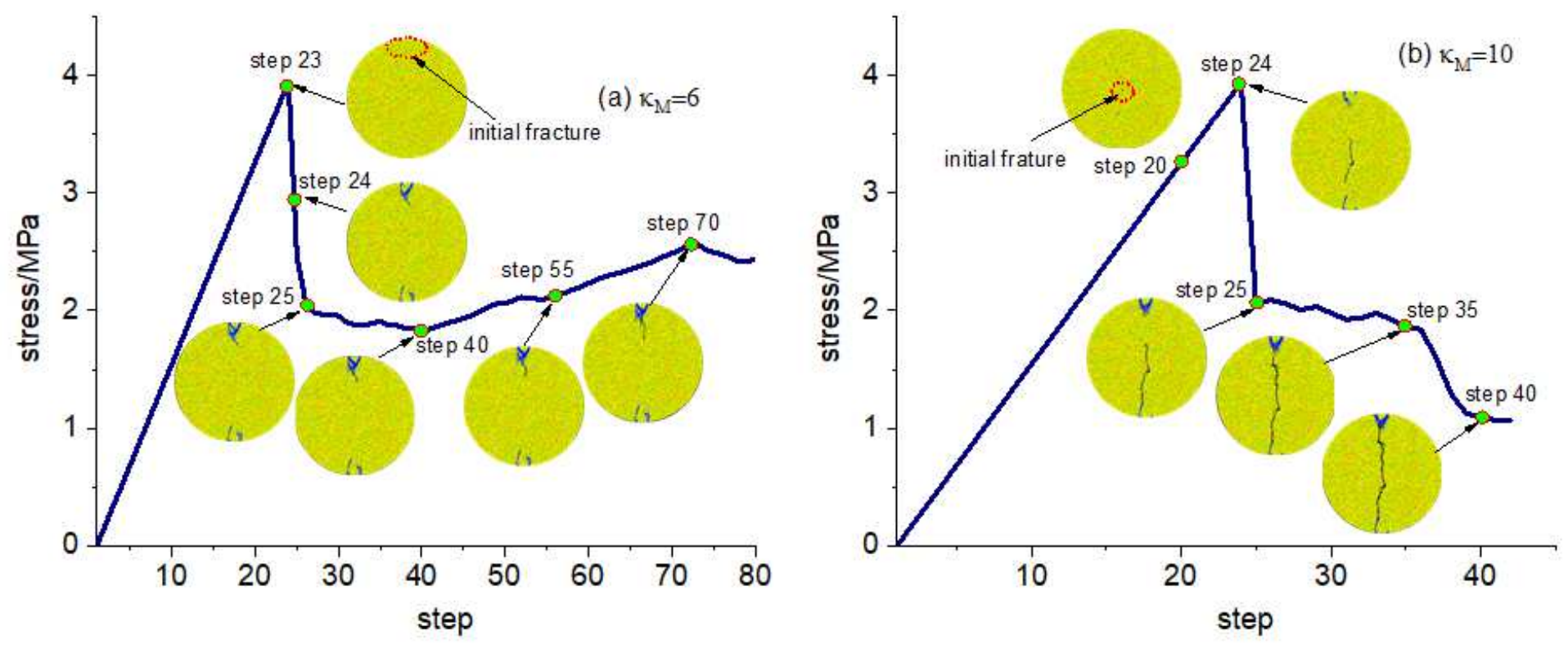

Figure 9

Effect of compression-tension ratios on the failure evolution process of Brazilian discs

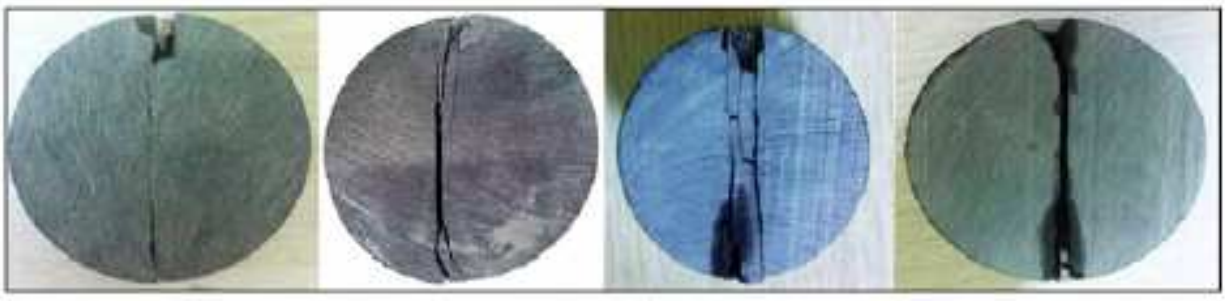

Figure 10

Split failure modes of Brazilian discs (Wang et al. 2017)

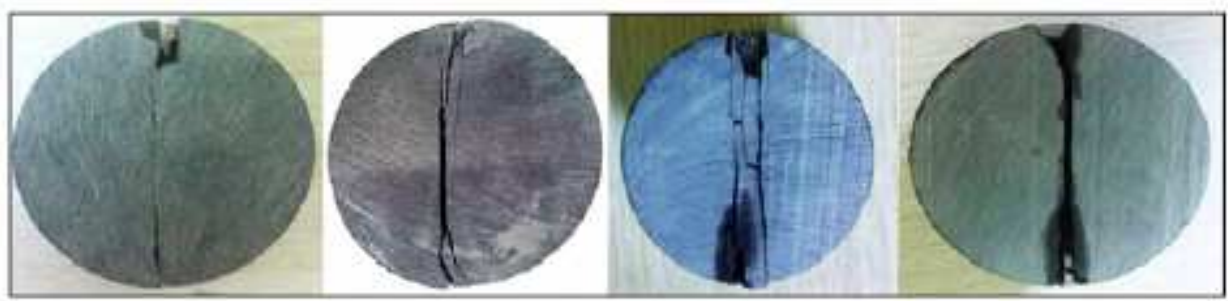

Figure 10

Split failure modes of Brazilian discs (Wang et al. 2017)

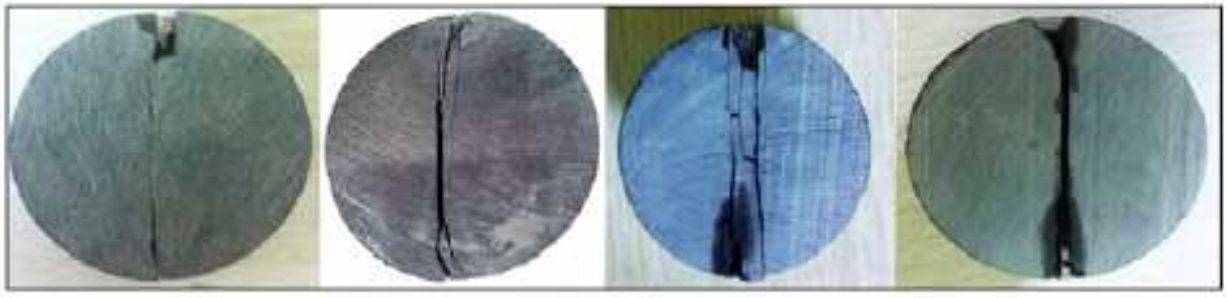


Figure 10

Split failure modes of Brazilian discs (Wang et al. 2017)

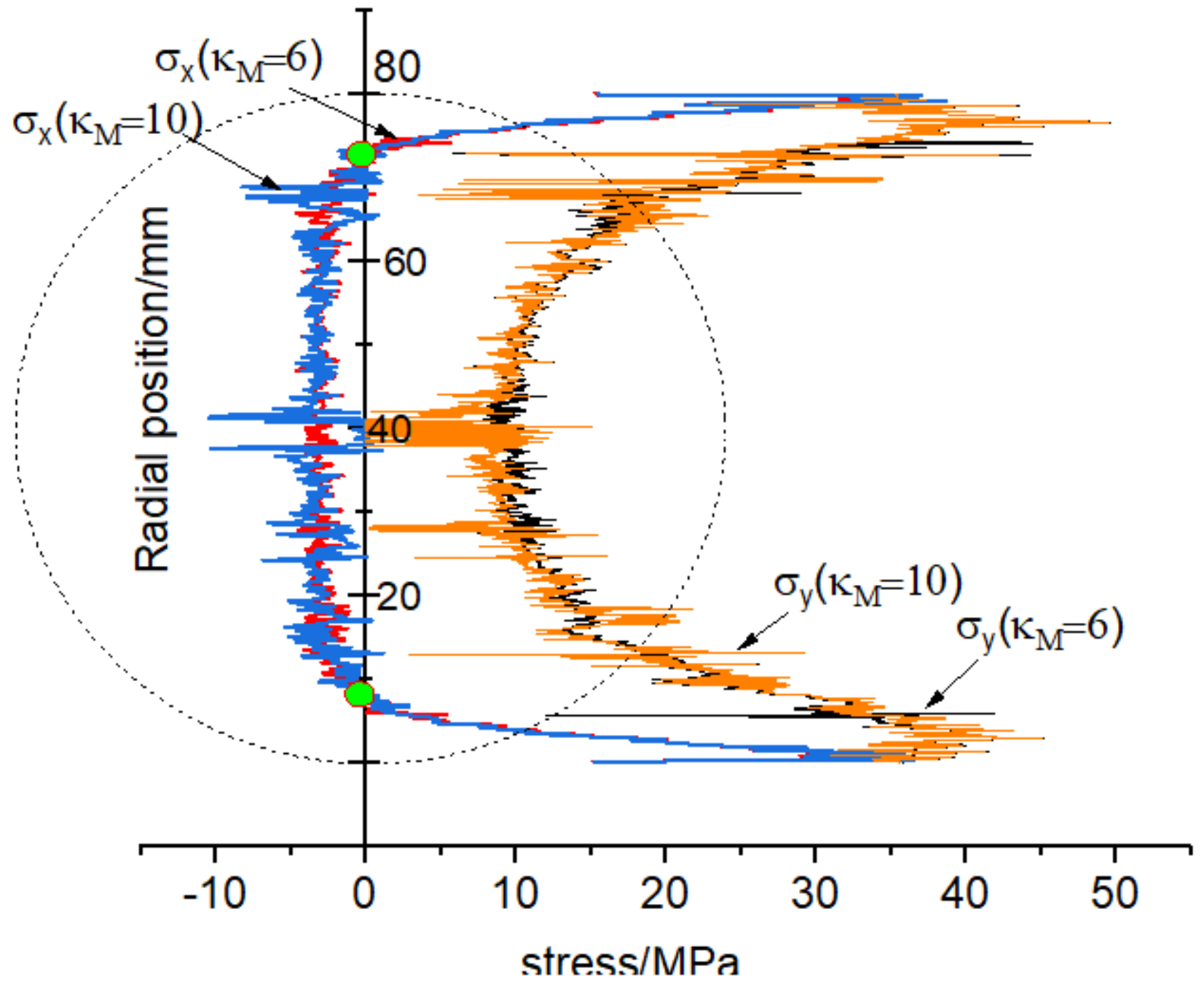

Figure 11

Stress distribution along loading diameter with different compression-tension ratios 


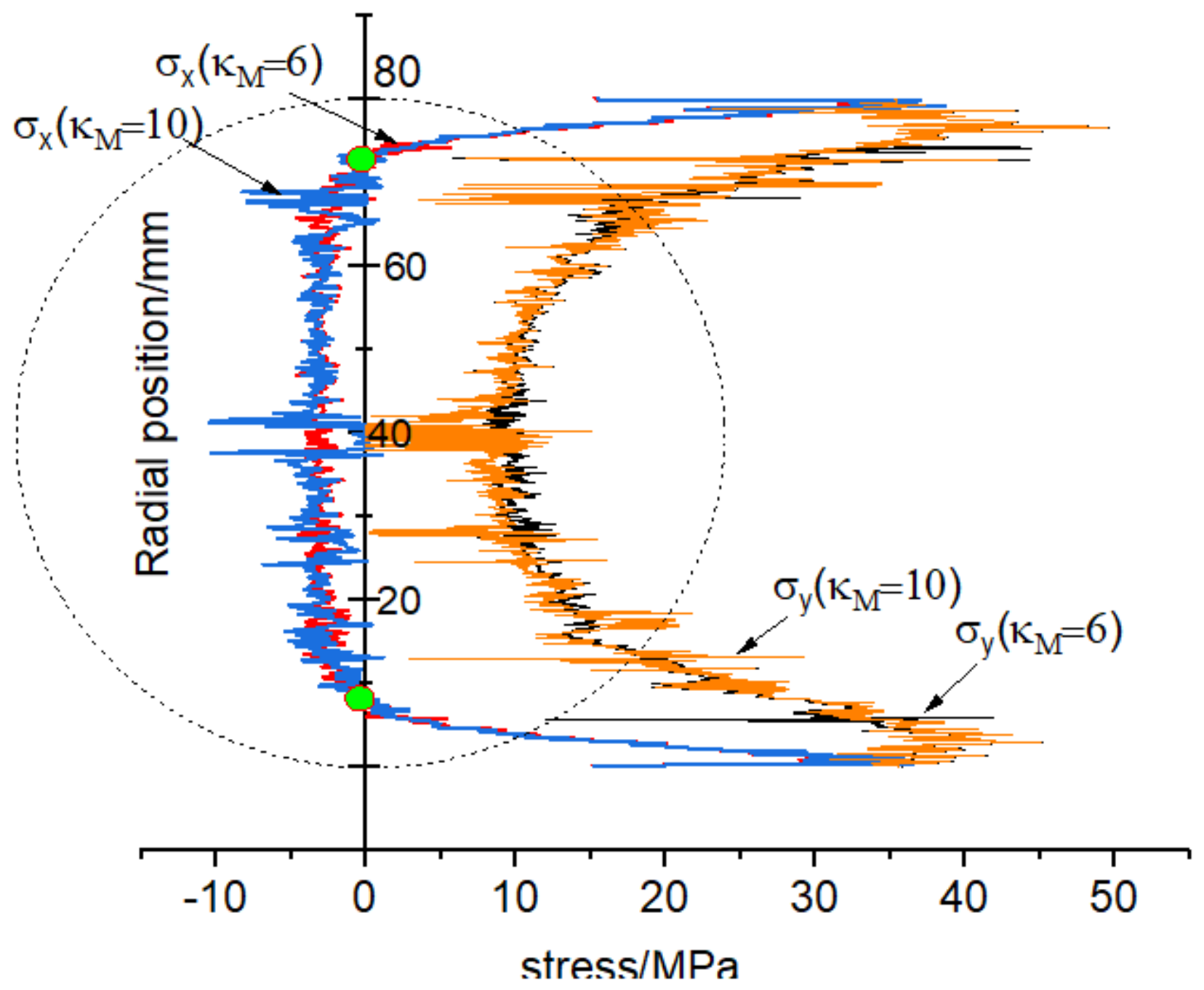

Figure 11

Stress distribution along loading diameter with different compression-tension ratios 


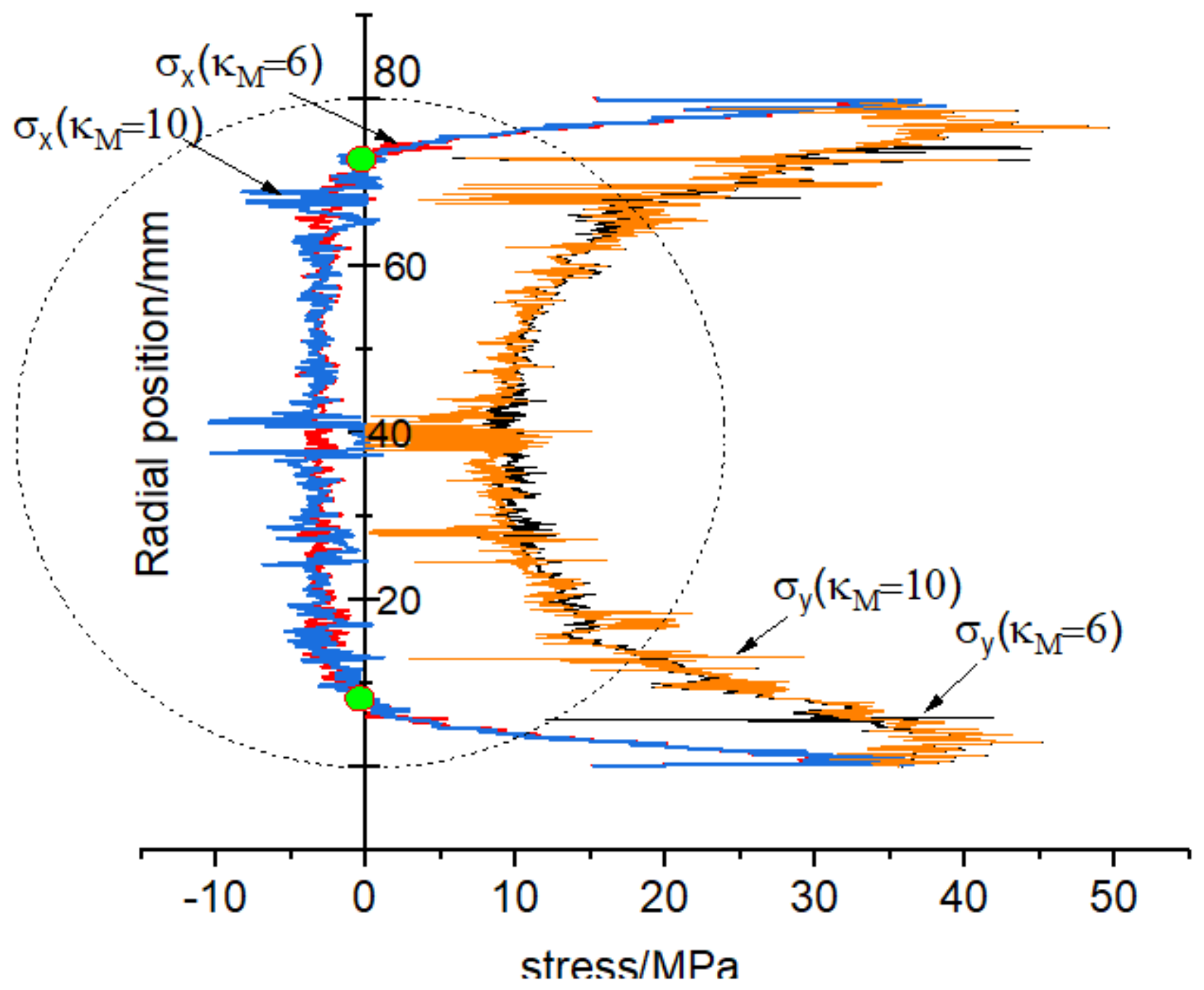

Figure 11

Stress distribution along loading diameter with different compression-tension ratios 